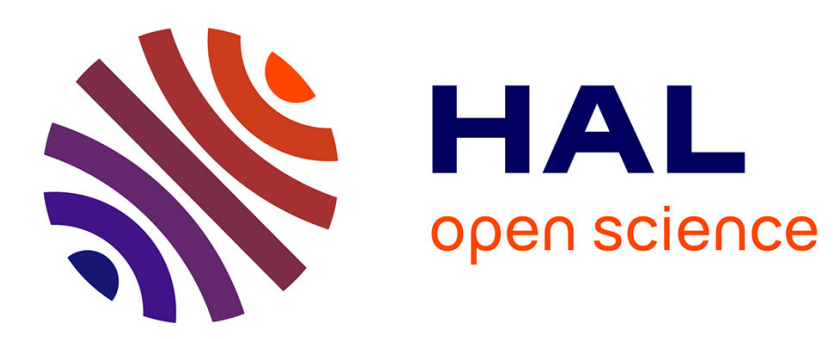

\title{
Well-being of elderly people living in nursing homes: The benefits of making friends
}

François-Charles Wolff

\section{To cite this version:}

François-Charles Wolff. Well-being of elderly people living in nursing homes: The benefits of making friends. 2012. hal-00759187

\section{HAL Id: hal-00759187 \\ https://hal.science/hal-00759187}

Preprint submitted on 30 Nov 2012

HAL is a multi-disciplinary open access archive for the deposit and dissemination of scientific research documents, whether they are published or not. The documents may come from teaching and research institutions in France or abroad, or from public or private research centers.
L'archive ouverte pluridisciplinaire HAL, est destinée au dépôt et à la diffusion de documents scientifiques de niveau recherche, publiés ou non, émanant des établissements d'enseignement et de recherche français ou étrangers, des laboratoires publics ou privés. 
EA 4272

\title{
Well-being of elderly people living in nursing homes: The benefits of making friends
}

\author{
François-Charles Wolff*
}

$2012 / 43$

* LEMNA, Université de Nantes et INED, Paris.

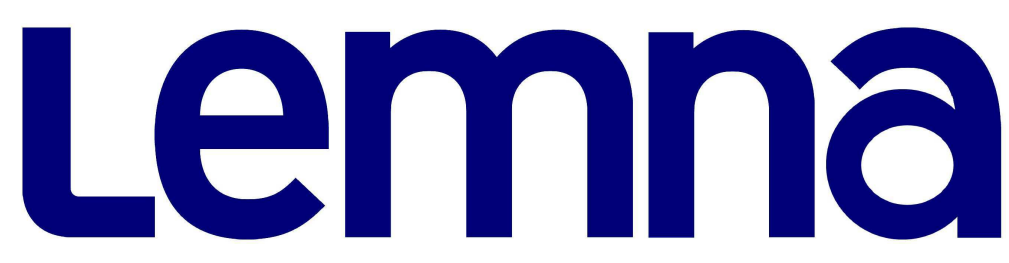

Laboratoire d'Economie et de Management Nantes-Atlantique Université de Nantes

Chemin de la Censive du Tertre - BP 52231

44322 Nantes cedex 3 - France

www.univ-nantes.fr/iemn-iae/recherche

UNIVERSITÉ DE NANTES

Tél. +33 (0)2 40141717 - Fax +33 (0)2 40141749 


\title{
Well-being of elderly people living in nursing homes: The benefits of making friends $\#$
}

\author{
François-Charles Wolff
}

September 2012

\begin{abstract}
Using French data collected in 2007 from a sample of about 2,000 elderly people living in nursing homes, this paper investigates the role that individual characteristics play in satisfaction with life and depression. Following psychological studies that have highlighted the benefits of social interactions on individual well-being, I focus in particular on the role played by making friends in the nursing home. Results from random effect ordered Probit models show that both satisfaction with living conditions and feeling of depression are much more influenced by making friends in the institution than by visits from family and relatives or other individual background characteristics. These findings may be interpreted as evidence of a relational return to friendship within nursing homes.
\end{abstract}

Keywords: friends, institutionalized elderly, living conditions, nursing home, relational goods

\footnotetext{
\# I would like to thank anonymous reviewers for their very hepful comments and suggestions on a previous draft. The usual disclaimer applies.

${ }^{*}$ Corresponding author. LEMNA, Université de Nantes, BP 52231 Chemin de la Censive du Tertre, 44322 Nantes Cedex 3 , France and INED, Paris, France.

E-mail: francois.wolff@univ-nantes.fr http://www.sc-eco.univ-nantes.fr/ fcwolff
} 


\section{Introduction}

The rapidly ageing worldwide population is creating a number of challenges for both developed and developing countries. According to the World Health Organization, this includes among others strains on social security systems and pensions, increasing demand for health care and rising needs for long-term care programs. Over the last few years, a number of studies have been conducted to identify factors associated to entry and living in institutions.

Entry into a nursing home strongly increases with age, especially among the oldest elderly. Women, married and healthy people are less likely to be institutionalized (Ness et al., 2004, Sarma and Simpson, 2007) ${ }^{1}$. Publicly provided home care and access to informal care affect living arrangement decisions. For instance, elderly with a greater number of living children enter a nursing homeless often (Jette et al., 1995). Significant differences have been reported between nursing home and community-residing elderly people, for instance in mortality risk (Van Dijk et al., 2005), health status (Asakawa et al., 2009), quality of life and well-being (McAuley et al., 2000, Gueldner et al., 2001, Borowiak and Kostka, 2004, Borg et al., 2006, Onishi et al., 2010).

With the increasing number of individuals in long-term care, a challenging policy objective consists of effectively managing elderly people's quality of life. Understanding factors associated with quality of life and life satisfaction of the institutionalized elderly is hence an important issue that has notably been under-investigated so far. Nowadays, nursing homes not only concentrate on prevention and treatment of chronic diseases and illnesses affecting the elderly, they also take into consideration the quality of life and life satisfaction of their own residents.

The specific purpose of my contribution is to examine the role of individual characteristics that contribute to life satisfaction and depression in nursing homes. My empirical analysis draws on data collected in France as this country is likely to experience one of the strongest increases in its retirement home population (Jacobzone et al., 2001). The situation of residents in retirement homes in France and especially their life satisfaction is poorly documented, which may be explained by the exclusion of institutionalized elderly from standard household surveys ${ }^{2}$. I focus in particular on the role played by social relationships and more precisely friends in the nursing home.

Several psychological studies have highlighted the benefits of social interactions on individual well-being, a mechanism called social resources by Musick and Wilson (2003). Following Baumeister and Leary (1995, p. 497), "human beings have a pervasive drive to form and maintain at least a minimum quantity of lasting, positive and significant interpersonal relationships". Social support has beneficial effects on a large set of physical health outcomes (Uchino et al., 1996), while social

\footnotetext{
${ }^{1}$ See Miller and Weissert (2000) for an overview of the predictors of institutionalization.

${ }^{2}$ In 1998, about 480,000 people over 60 were in retirement homes or long-term care facilities and most residents were satisfied with their accommodation (Dufour-Kippelen and Mesrine, 2003).
} 
isolation is depressing (Mirowsky and Ross, 1989). The reduction in social contact has been proved an important predictor of cognitive decline (Penninx, 1997).

A few economists have also argued that interpersonal contact matters in its own right (Kolm, 2000, Gui, 2000). This refers to the concept of relational goods, which may be seen as intangible outputs produced through interactions (Uhlaner, 1989). Both in France and in Italy, Prouteau and Wolff (2004) and Degli Antoni (2009) find that people volunteer in order to increase their social network, especially for intrinsically motivated volunteers. Using data from Germany, Becchetti et al. (2008) show that activities producing relational goods have significant and positive effects on selfassessed life satisfaction. The effect of sociability on happiness tends to be stronger for women, older and less educated people.

In what follows, I hypothesize that the benefits of social interactions that people have with others and especially with friends should be large among institutionalized elderly. To assess the causal benefit of making friends in the institution, I consider a French survey conducted in 2007 on a sample of about 2,000 elderly people living in retirement homes or long-term care units. For each respondent, the questionnaire includes ordered indicators on the well-being in the institution and on the feeling of sadness or depression. It also indicates whether the respondent has made any friends in the institution. As the data includes several residents per nursing home, I estimate random effect ordered Probit models to study the role of individual characteristics on well-being.

My main results are that both satisfaction with living conditions and feelings of sadness or depression are much more influenced by making friends in the institution than by visits from family and relatives. This pattern is robust to problems of measurement error, unobserved heterogeneity and simultaneity. The remainder of my paper is organized as follows. In Section 2, I describe the data and living conditions of elderly people living in institutions in France. Section 3 investigates the determinants of subjective well-being among elderly residents and provides several robustness checks related to endogeneity issues. Section 4 concludes.

\section{Data and descriptive statistics}

\section{II.1. The SAEP survey}

I study the well-being of elderly people living in institutions using a survey conducted in France by the Direction of Research, Studies, Evaluation and Statistics (DRESS) in 2007. This survey entitled "Residents in Sheltered Accommodation for Elderly People" (SAEP hereafter) concerns a representative sample of respondents living either in traditional retirement homes, in retirement homes for dependent elderly people, in sheltered accommodation or in long-term care units. Its main purpose was to describe both the entry and the current living conditions of residents in SAEP 
and to assess the quality of their care in these institutions. The sample of the SAEP survey was constructed in the following way.

First, information was collected from 433 institutions about their own residents. For each institution, a random sample of eight residents was selected to take part in the SAEP survey. Both institution heads and nursing staff had to assess whether these residents were able or not to answer the questionnaire by themselves. The staff had also to give the address and details of a person close to the resident, defined as "someone who knows the resident well, has good relations with him/her and visits him/her regularly". Among the 3,464 potential residents, 1,802 were directly interviewed and 2,066 proxy respondents were interviewed, either in place of or in addition to the resident. The SAEP survey comprises 2,742 observations, with 1,126 questionnaires in duplicate (completed by both the resident and the proxy respondent).

I rely on the following ordered indicators to study the well-being of elderly people living in a care-giving institution. The first question is about current living conditions: "how is your life in this institution?". Possible answers are "very bad", "rather bad", "rather good", "very good". I also know how the resident felt about his/her first moments spent in the institution, with the same set of outcomes ranging from "very bad" to "very good". The second question is about sadness and depression: "do you feel sad, distressed or depressed?". Possible answers are "always", "often", "sometimes", "never". In both cases, similar questions were asked to the proxy respondent on behalf of the resident.

I considered the following individual characteristics to explain the well-being indicators: gender, age, born in France, marital status, number of children, last occupation if any (a proxy for socio-economic status), and health which is expected to have a strong influence on living conditions during old age. As self-assessed measures of health are likely to be contaminated by subjectivity bias, I consider a more objective indicator describing the state of dependency of each resident. The IsoResources Group (IRG) outcome is assessed by a medico-social team and relies on a set of discriminatory factors regarding the loss of physical and psychological independence like orientation or coherence. Each resident is classified into one of six groups depending on loss of independence ${ }^{3}$.

As I am interested in the role of social relationships on well-being, I constructed a dummy variable which is equal to one when the respondent has made friends with the other residents and zero otherwise. This information is provided both by residents who were directly interviewed and by proxy respondents when residents were not in a position to fill in the questionnaire by themselves.

\footnotetext{
${ }^{3}$ Group 1 corresponds to people who are bed-ridden or chair-ridden and have lost their mental and physical independence. Group 2 includes people who are bed-ridden or chair-ridden and require assistance with daily activities, but whose mental capacity is not completely affected. It also comprises people who are able-bodied, but whose mental capacity is affected. People in group 3 are mentally autonomous, but require assistance with their physical autonomy, daily and several times per day. People in group 4 can move inside the accommodation after rising, but need help washing and dressing themselves. Finally, people from group 5 and 6 are respectively very slightly and not at all dependent.
} 
Another question is about whether the resident receives visits from relatives, but this question was not asked to proxy respondents ${ }^{4}$. I again constructed a dummy variable when the respondent reported such visits. Residents further indicated whether the frequency of these visits was right for them or whether they would have appreciated receiving more visits from relatives. In what follows, I will study the effect of these social relationships on the well-being of residents.

I restricted the sample in the following way. I deleted respondents younger than 60 years $(\mathrm{N}=42)$ and observations with unknown IRG score $(\mathrm{N}=119)$. I also excluded residents or proxy respondents who did not provide information on living conditions and depression ( $N=338)$. This left me with a sample of 2,243 residents belonging to 418 SAEP. The mean number of residents with complete questionnaire data is 5.4 per SAEP.

\section{II.2. Living conditions in French institutions}

According to the SAEP survey, elderly people in French institutions were on average satisfied or very satisfied with their current living conditions. One-half of them claimed that they lived rather well and $36.3 \%$ that they lived very well. The proportion of unsatisfied residents is $13.3 \%$, a very small proportion (2.5\%) living very badly in their institution. The same pattern is found for the sadness/depression indicator. About one-quarter of residents always (6.1\%) or often (19.2\%) felt sad, distressed or depressed, while $28.4 \%$ did not have such feelings. I found that about $70 \%$ of respondents both lived well or very well and were sometimes or never sad/depressed.

It is interesting to compare the well-being of nursing home people to the general population. Drawing on the Eurobarometer surveys, Afsa and Marcus (2008) show that the proportion of respondents being either very or rather satisfied with their life (whatever their age) was between 70\% and 80\% from 1975 to 2000 in France. I find a slightly higher proportion of residents living well in nursing home (around $85 \%$ ), but satisfaction with living conditions and satisfaction with life satisfaction may sound like different concepts for residents. When taking age into account, Afsa and Marcus (2008) show that life satisfaction strongly reduces after 68 years old. Using data collected in 2010, Godefroy (2011) finds a very similar pattern. In particular, people aged above 80 years old have much lower levels of satisfaction on average.

In Figure 1, I present the pattern of both living conditions when entering the nursing home and current living conditions. Residents are on average more satisfied now with their living conditions than during the first moments after their admission to a home. There are many more residents living very well now than after entry (36.3\% compared to $25.9 \%$ ). When crossing both measures, simple calculations show that life satisfaction remains unchanged for $58.4 \%$ of residents,

\footnotetext{
${ }^{4}$ By definition, proxy respondents are relatives of the non-interviewed resident. $95 \%$ of them are members of the family and $69 \%$ are children of the residents.
} 
while it improves more frequently than it worsens (respectively $31.4 \%$ and $10.2 \%$ ). Several explanations may come to mind to explain this pattern.

\section{Insert Figure 1}

As age increases, being placed in a nursing home is a hard decision to take as nursing homes are often seen as being the stopover point prior to death. Elderly people could thus be apprehensive especially if they have the feeling they are losing part of their independence by leaving their own home. At the same time, people are often placed in nursing homes when their ageing process is affected by several illnesses and medical conditions. Due to this selection effect, their well-being is likely to improve once they are receiving the quality of care they deserve. After a while, living in a nursing home may also offer new perspectives for residents. Many nursing home facilities offer residents a full range of activities and elderly people could be happy to be involved in these activities. In particular, this may offer opportunities to make friends in the home.

I describe the relationship between subjective well-being and making friends in Figure 2 . The SAEP data shows a positive correlation between having made friends in the institution and wellbeing. The proportion of respondents claiming that they live very well in their nursing home is $42.1 \%$ when residents have made friends, but only $20.9 \%$ otherwise. Residents are much more likely to live badly or very badly when they have no friends, $23.7 \%$ instead of $9.5 \%$. The same pattern is found for sadness/depression. The gap between residents with and without friends remains large, $30.1 \%$ compared to $20.4 \%$. Interestingly, the influence of friends on well-being seems much larger than that of visits from family. On the basis of statements from directly interviewed residents, I find that the proportion of residents living very well is only six points higher among those receiving visits from family members (37.4\% instead of $31 \%)$. Besides, the proportion of residents being always or often sad or distressed is nearly the same with or without family visits.

Insert Figure 2

The positive correlation between making friends and subjective well-being supports several interpretations. On the one hand, there may be a relational return to friendship, so that residents would themselves feel better when they have friends to share all of life's ups and downs. On the other hand, the positive correlation may be due to heterogeneity in individual characteristics. If there are factors that influence both the determinants of living conditions and having friends, then the positive relation between these outcomes could be spurious. For instance, residents in better health should on average live better than those in poor health. At the same time, they are certainly more likely to make friends by taking part in guided activities offered in the nursing home.

A description of the sample shows the need to account for heterogeneity when explaining subjective well-being among elderly nursing home residents. According to Table 1, residents living well or very well are slightly older. They are on average in better health and are over-represented in 
sheltered accommodation. Residents who are sometimes or never concerned by sadness or depression are more often women or single. They have lower IRG scores than depressed residents, while the type of SAEP plays no role. It is hence important to account for individual characteristics when explaining subjective well-being of elderly people living in nursing homes.

Insert Table 1

\section{The determinants of subjective well-being among elderly residents}

\section{III.1. Econometric specification}

I rely on an econometric analysis to study the relationship between well-being and making friends. Two sets of factors are expected to influence living conditions of nursing home resident elderly: individual characteristics and the specific features of the nursing home. In what follows, I draw on panel data techniques to account for both unobserved and observed characteristics of institutions. I simply exploit the fact that the SAEP survey includes data on several residents per nursing home.

For the presentation, let $W^{k}$ be an indicator of well-being, respectively living conditions $(k=L C)$ and sadness/depression $(k=S D)$, such that $W^{L C}=1$ when the resident lives "very badly", $W^{L C}=2$ when "badly", $W^{L C}=3$ when "well", and $W^{L C}=4$ when "very well". Similarly, $W^{S D}$ ranges from 1 when the resident is always sad/depressed to 4 when this is never the case. Let $W^{k *}$ be two latent variables associated to these subjective indicators $(k=L C, S D)$. I assume that $W^{k *} \leq \mu_{1}^{k}$ when $W^{k}=1, \mu_{1}^{k}<W^{k *} \leq \mu_{2}^{k}$ when $W^{k}=2, \mu_{2}^{k}<W^{k *} \leq \mu_{3}^{k}$ when $W^{k}=3$, and $\mu_{3}^{k}<W^{k *}$ when $W^{k}=4$. I consider a linear expression for the latent outcome:

$$
W_{j i}^{k *}=X_{j i} \beta+\theta F_{j i}+\delta_{j}+\varepsilon_{j i}
$$

where $j$ and $i$ as subscripts refer respectively to the nursing home and to the resident, $X$ is a set of individual characteristics, $F$ is a dummy indicating whether the resident has made friends in the institution, $\beta$ and $\theta$ are parameters to estimate, and $\delta$ and $\varepsilon$ are error terms. In (1), $\delta_{j}$ is an unobserved nursing home effect. It will, for instance, pick up the various facilities at the disposal of residents inside the institution, adequateness of the staff including size of the nursing staff, presence of a dietician, occupational therapist or recreational advisor, activities the facility encourages the residents to be part of, the possibility of having safe and comfortable rooms, the fact that residents may be allowed to move in furniture items from their own home, the type of food served, etc.

I suppose that $\delta_{j} \sim N\left(0 ; \sigma_{\delta}^{2}\right)$ and $\varepsilon_{j i} \sim N(0 ; 1)$. Under the assumption that the individual characteristics are uncorrelated with the nursing home effects, (1) defines a random effect ordered Probit model. This implies that the different threshold levels $\mu^{k}$ have to be estimated jointly with the 
parameters of interest $\beta$ and $\theta$. Since the likelihood function involves multivariate normal integrals, the ordered Probit model is estimated using quadrature techniques (Butler and Moffit, 1982).

\section{III.2. Random effect estimates of subjective well-being}

Table 2 presents the random effect ordered estimates respectively for living conditions (part A) and sadness/depression (part B), higher scores being associated with higher subjective wellbeing ${ }^{5}$. Let me first consider living conditions. According to the estimates, it appears somewhat difficult to explain whether residents live well or badly in their current location on the basis of their individual characteristics. Gender, age, place of birth and number of children do not matter (column 1A). Single residents live slightly better, but the relationship is hardly significant. The most influential predictor of living conditions is the IRG score. Not surprisingly, those who are in better health claim that they live better on average.

\section{Insert Table 2 here}

Residents living in sheltered accommodation are also better off, which could be evidence of some selection effect. Less well off elderly people are more likely to be placed in retirement homes or in long term care units, while sheltered accommodation is more designed to be an intermediate step between the resident's original home and a traditional retirement home. It will appeal to old people who are able-bodied, but are no longer able to (or do not want to) live by themselves. Finally, answers about living conditions are not different when being provided by the residents themselves or by proxy respondents.

In column (2A), I introduce the presence of friends in the different environments. I find a large positive correlation between having friends and living conditions. Doing as if the dependent variable were continuous, random effect least square estimates indicate that living conditions improve by $33.4 \%$ when residents have made friends in their new place of residence. This is simply the most influential covariate when explaining living conditions, far beyond the other explanatory variables. For the sake of comparison, I investigate the role of visits from family members and relatives. As, by definition, such visits exist in the case of proxy respondents, I only consider the subsample of residents answering the questionnaire by themselves.

Receiving visits from family and relatives also significantly improves well-being (column 3A). However, the coefficient associated to having friends is much higher than that of the family and

\footnotetext{
${ }^{5}$ In both cases, there is little variation in the mean level of well-being of residents between the various nursing homes. The ratio $\rho=\sigma_{\delta}^{2} /\left(1+\sigma_{\delta}^{2}\right)$ ranges from 0.02 to 0.11 , meaning that the within unexplained variance $\sigma_{\delta}^{2}$ is much lower than 1 . There are hence large unexplained variations in subjective well-being between residents living in a given nursing home in France.
} 
relatives ${ }^{6}$. Results from random effect linear models show that the marginal effect of family visits (11.3\%) is more than three times lower than that of having friends. Residents further indicate whether they are satisfied or not with the frequency of visits from family or relatives. I find that residents claim living better only when they are satisfied with the frequency of family visits. When they are not satisfied, their level of well-being tends to be slightly lower (column 4A).

I then investigate sadness and depression determinants (part B, Table 2). On average, women are more often sad or depressed than men (column 1B). Older, single and divorced residents are less subject to sadness/depression, while having children has no influence. Those being in better physical health (measured by the IRG score) are also less affected by mental difficulties. Contrary to what was observed for living conditions, there is no difference in mental health by type of institutions while the presence of proxy respondents is now significant. Proxy respondents are less optimistic about the well-being of the residents as they assess the latter as more often distressed or depressed.

I add in column (2B) the dummy variable associated to friends. As observed for living conditions, having friends within the nursing home significantly improves the feeling of not being sad or depressed. Estimates from a random effect linear model suggest that not having friends increases the propensity for feeling sad or depressed by about $20 \%$. At first viewing, sadness and depression are not affected by visits received by family and relatives among self-interviewed residents (column 3B). Nevertheless, a more accurate look at the data shows that there is a significant relationship between these visits and sadness/depression only when residents are satisfied with the frequency of visits. When they are not satisfied, residents feel sad or depressed more often, which could be due to the frustration of not having enough contact with family and relatives.

\section{III.3. Endogeneity issues}

The ordered estimates suggest that having friends in the nursing home has a beneficial effect on the subjective well-being of institutionalized elderly. With respect to the previous regressions, a question worth is to know whether the dummy variable associated to friends can really be treated as exogenous. Endogeneity may be due to one of the following reasons: measurement errors, unobserved heterogeneity and simultaneity.

Let me first focus on measurement errors. The main difficulty lies with the presence of proxy respondents, as the latter may have a less accurate perception of the resident's situation. Spending a long time in the institution is needed for proxy respondents to know whether residents have made friends or not, but a correct assessment of their living conditions may still be uneasy without sharing their daily activities or meals. Interestingly, the SAEP data shed light on the divergence in answers

\footnotetext{
${ }^{6}$ A Wald test indicates that the two coefficients are significantly different. I obtain a value of 86.6 for the corresponding statistic, with 1 degree of freedom.
} 
that may occur because of proxy respondents. By definition, I have questionnaires completed by both the resident and a proxy respondent in 1,039 cases. When comparing their answers, I observe substantial differences for several outcomes.

Among directly interviewed residents, $78.7 \%$ of them report having friends in the home. This proportion is more than four percent higher (83.1\%) according to proxy respondents. However, the corresponding crossed table shows that the proportion of concordant answers is around $76 \%$. So, measurement errors occur in about one case over four when drawing on information provided by proxy respondents instead of answers from residents themselves. The situation is even worse for the indicator of living conditions since only $53.4 \%$ of answers are similar. Nevertheless, differences remain tenuous as they essentially concern whether residents live well or very well?.

A solution to the problem set by measurement errors consists in excluding the cases with proxy respondents, which is done in columns (1A), (2A), (1B) and (2B) of Table 2. In these random effect regressions, I obtain a large marginal effect of friends on well-being. At the same time, this leads to sample selection since residents in poor or very poor health are less likely to be interviewed. Estimates in columns $(3 \mathrm{~A})$ and $(3 \mathrm{~B})$ have then to be seen as upper bounds since they will pick up the returns of making friends among the healthiest nursing home residents. To further highlight this result, $I$ introduce an additional crossed term in (2A) and (2B) which is equal to one when the resident has friends and answers are provided by proxy respondents. In both cases, I find significant values for the crossed term (at $10 \%$ for sadness/depression), meaning that the marginal effect of making friends is lower when the resident is unable to answer to the questionnaire by himself/herself ${ }^{8}$.

The second concern is about omitted variables. Although the random effect regressions account for unobserved heterogeneity, these specifications may lead to biased estimates if the institution effects are correlated with the explanatory variables. This could occur for instance if residents locate in specific institutions depending on their health status. I have thus also considered a fixed effect framework, drawing on the conditional estimator proposed in Das and Van Soest (1999) These estimates, not reported, show that my previous findings remain valid with the fixed effect specification.

I find that within nursing homes, residents having made friends live much better on average. After excluding proxy respondents, living conditions are positively correlated with visits from family

\footnotetext{
${ }^{7} 16.8 \%$ of residents claim that they live very well while proxy respondents believe they live well. In the same way, $13.1 \%$ of residents claim to live well when proxy respondents think they live very well.

${ }^{8}$ These additional results are available upon request. For living conditions, the coefficient associated to the crossed term is equal to -0.284 ( $t=-2.44)$ while the coefficient associated to having friends is 0.631 .

${ }^{9}$ In a first step, I estimate a set of fixed effect Logit models by grouping together adjacent outcomes related respectively to living conditions or sadness/depression. Then, I rely on a classical minimum distance estimator. Results from the ordered fixed effect regressions are available upon request.
} 
and relatives, but the corresponding marginal effect is twice as low as that of friends. Making friends also reduces the feeling of being sad or depressed. Further, I find that answers from proxy respondents strongly reduce the propensity of not being sad or depressed. This is evidence that proxy respondents tend to have a more pessimistic view on the psychological difficulties of residents than the latter have.

The last issue that could lead to endogeneity bias is simultaneity. In particular, reverse causality could explain the positive correlation between making friends and current living conditions if elderly people living well make friends more easily. Residents smiling and feeling happy when entering the nursing home will certainly be perceived as more attractive by other residents, which would increase the likelihood of establishing friendly relationships. The survey allows me to further study the relevance of these two competing interpretations, i.e. having friends increases the subjective well-being of residents versus residents living better make friends more easily.

In the SAEP survey, residents are asked about their living conditions just after entering the institution. This initial state is unlikely to be contaminated by the impact of making friends in the nursing home. As a consequence, I account for the fact that more well-off elderly people could make friends more easily by adding their initial state of living conditions into the regression. I first reestimate the random effect ordered Probit regression on the subsample of 2,176 residents with information on both current and initial living conditions. I find a coefficient equal to 0.550 ( $t=9.52)$ for the friends dummy, which is very close to the estimate reported in column (2A) of Table 2. Then, I add initial living conditions in the regression. These estimates, available upon request, leads to the two following results.

First, I find that assessment about living conditions when entering the nursing home strongly influences current living conditions (state dependence). Secondly, I get a slightly lower coefficient for the friends dummy (0.439 instead of 0.550$)$, but the covariate remains highly significant $(t=7.35)$. From random effect linear estimates, this would correspond to a fall of $28.5 \%$ in the return of having friends on current living conditions (from $34.7 \%$ to $24.8 \%$ ). The fall is even slightly higher (31.1\%) when excluding proxy respondents from the sample. Having friends in the institution increases the indicator of living conditions when initial living conditions are taken into account by $27.2 \%$ (instead of $39.5 \%$ without initial living conditions). These results suggest that residents living better when entering the nursing home make friends more easily after a while.

However, the positive effect of making friends still remains. I further investigate the dynamics in living conditions by estimating the difference between current and initial living conditions as a function of individual characteristics and having friends. If my interpretation in terms of social relationships is correct, then I should observe that having made friends during the stay in nursing home has, on average, improved living conditions among residents. As there are very few 
extreme values, I recode the dependent variable defined as the difference between initial current and living conditions so that it ranges from -2 to $2^{10}$.

Residents with a positive value (31.4\%) live better in the nursing home now than just after their entry. Since the dependent variable is ordered, I again turn to ordered Probit models and account for unobserved heterogeneity at the institution level using random effect models ${ }^{11}$. Given my previous results, I rely on a small number of covariates and consider the following covariates: gender, age, IRG score, years in the retirement home, questionnaire completed by a proxy respondent and making friends.

As shown in Table 3, I find that years spent in the retirement home are negatively related to changes in well-being, while other individual characteristics do not matter. Residents who have made friends in the nursing home report more often improved living conditions according to the random effect estimates (column 1). Excluding proxy respondents from the sample does not affect this conclusion (column 2), making friends remaining significant at the five percent level.

\section{Insert Table 3}

\section{Conclusion}

According to demographic projections, the number of elderly people living in retirement or nursing homes should strongly increase in many developed countries over the coming years. While this phenomenon will put a strong pressure on the number of places available in nursing homes, another issue that deserves researchers' attention is the quality of life and well-being of institutionalized elderly as it has an impact on both their physical and mental health. In this paper, I have used recently collected data from France to investigate the factors influencing life satisfaction and depression of elderly people living in retirement homes or long-term care units.

Following psychological studies that have highlighted the benefits of social interactions on individual well-being, I have put emphasis on the role played by making friends in nursing home. My main results are that both satisfaction with living conditions and feelings of sadness or depression are much more influenced by making friends in the institution than by visits from family and relatives or by any other individual background characteristics. These findings, which are robust to problems of measurement errors, unobserved heterogeneity and simultaneity, may be interpreted as evidence of a relational return to friendship within nursing homes.

From a public policy viewpoint, my results suggest that the quality of life of retirement or nursing home residents could be improved using simple solutions. For instance, promoting very

\footnotetext{
${ }^{10}$ According to the data, six residents are characterized by a difference of -3 and 16 by a difference of 3 . The proportion of residents with a difference of -2 is $2.2 \%, 10.2 \%$ for $-1,58.4 \%$ for $0,25.6 \%$ for 1 and $5.8 \%$ for 2 .

${ }^{11}$ I have also estimated fixed effect regressions. These estimates (available upon request) show that making friends in the institution improves assessment on living conditions only among residents who were directly interviewed.
} 
regularly social or recreational activities that allow frequent meetings and interactions between residents, including those recently entered into the nursing home, is likely to enhance interpersonal relationships and friendship without requiring too many additional expenditures from the nursing staff. These are undoubtedly opportunities of interest in a context where developed countries have to deal with the challenging burden of increasing spending on long term care due to the ageing of their populations. 


\section{References}

Afsa, Cédric and Vincent Marcus (2008). Le Bonheur Attend-Il le Nombre des Années ?, in: INSEE, France, Portrait Social. Insee Références: 163-174.

Asakawa, Keiko, David Feeny, Ambikaipakan Senthilselvan, Jeffrey A. Johnson and Darryl Rolfson (2009). Do the Determinants of Health Differ Between People Living in the Community and in Institutions ?, Social Science and Medicine. 69: 345-353.

Baumeister, Roy F. and Mark R. Leary (1995). The Need to Belong : Desire for Interpersonal Attachment as a Fundamental Human Motivation, Psychological Bulletin. 117: 497-529.

Becchetti, Leonardo, Alessandra Pelloni and Fiammetta Rossetti (2008). Relational Goods, Sociability and Happiness, Kyklos. 61: 343-363.

Borg, Christel, Ingalill R. Hallbergl. and Kerstin Blomqvist (2006). Life Satisfaction among Older People (65+) with Reduced Self-Care Capacity: The Relationship to Social, Health and Financial Aspects, Journal of Clinical Nursing. 15: 607-618.

Borowiak, Ewa and Tomasz Kostka (2004). Predictors of Quality of Life in Older People Living at Home and Institutions, Aging Clinical and Experimental Research. 16: 212-220.

Butler, J.S. and Robert Moffitt (1982). A Computationally Efficient Quadrature Procedure for the OneFactor Multinomial Probit Model, Econometrica. 50: 761-764.

Chamberlain, Gary (1980). Analysis of Covariance with Qualitative Data, Review of Economic Studies. 47: 225-238.

Das, Marcel and Arthur van Soest (1999). A Panel Data Model for Subjective Information on Household Income Growth, Journal of Economic Behavior and Organization. 40: 409-426.

Degli Antoni, Giacomo (2009). Intrinsic vs. Extrinsic Motivations to Volunteer and Social Capital Formation, Kyklos. 62: 359-370.

Dufour-Kippelen, Sandrine and Annie Mesrine (2003). Les Personnes Agées en Institution, Revue Française des Affaires sociales. 1: 123-148.

Godefroy, Pascal (2011). Satisfaction dans la Vie: Les Personnes se Donnent 7 sur 10 en Moyenne, in: INSEE, France, Portrait Social. Insee Références: 105-118.

Gueldner, Sarah H., Susan Loeb, Diana Morris, Janice Penrod, Martha Bramlett, Linda Johnston and Patricia Schlotzhauer (2001). A Comparison of Life Satisfaction and Mood in Nursing Home Residents and Community-Dwelling Elders, Archives of Psychiatric Nursing. 15: 232-240.

Gui, Benedetto (2000). Beyond Transactions: On the Interpersonal Dimension of Economic Reality, Annals of Public and Cooperative Economics. 71: 139-169.

Jacobzone, Stephane, Emmanuelle Cambois and Jean-Marie Robine (2000). Is the Health of Older Persons in OECD Countries Improving Fast Enough to Compensate for Population Ageing?, OECD Economic Studies. 30: 149-190.

Jette, Alan M., Sharon Tennstedt and Sybil Crawford (1995). How Does Formal and Informal Community Care Affect Nursing Home Use?, Journal of Gerontology. 50: S4-S12.

Kolm, Serge-Christophe (2000). The Theory of Reciprocity, in: Louis-André Gérard-Varet, SergeChristophe Kolm and Jean Mercier-Ythier (eds.), The Economics of Reciprocity, Giving and Altruism. MacMillan Press: 115-141.

McAuley, Edward, Bryan Blissmer, David X. Marquez, Gerald J. Jerome, Arthur F. Kramer and Jeffrey Katula (2000). Social Relations, Physical Activity, and Well-Being in Older Adults, Preventive Medicine. 31: 608-617. 
Meier, Stephan and Alois Stutzer (2008). Is Voluntering Rewarding in Itself ?, Economica., 75: 39-59.

Miller, Edward A. and William G. Weissert (2000). Predicting Elderly People's Risk for Nursing Nome Placement, Hospitalization, Functional Impairment, and Mortality: A Synthesis, Medical Care Research and Review. 57: 259-297.

Mirowsky, John and Catherine E. Ross (1989). Social Causes of Psychological Distress, Aldine de Gruyter.

Musick, Marc A. and John Wilson (2003). Volunteering and Depression: The Role of Psychological and Social Resources in Different Age Groups, Social Science and Medicine. 56: 259-269.

Ness, Jose, Ali Ahmed and Wilbert S. Aronow (2004). Demographic and Payment Characteristics of Nursing Home Residents in the United States: A 23-year trend, Journal of Gerontology: Medical Sciences. 59A: 1213-1217.

Onishi, Chiemi, Kyoko Yuasa, Masako Sei, Ashraf Ewis, Takuro Nakano, Hokuma Munakata and Yutaka Nakahori (2010). Determinants of Life Satisfaction among Japanese Elderly Women Attending Health Care and Welfare Service Facilities, Journal of Medical Investigation. 57: 69-80.

Penninx, Brenda W., Theo van Tilburg, Didi M. Kriegsman, Dorly J. Deeg, Joan P. Boek and Jacques van Eijk (1997). Effects of Social Support and Personal Coping Resources on Mortality in Older Age: The Longitudinal Aging Study Amsterdam, American Journal of Epidemiology. 146: 510-519.

Prouteau, Lionel and François-Charles Wolff (2004). Relational Goods and Associational Participation, Annals of Public and Cooperative Economics. 75: 431-463.

Sarmaa, Sisira and Wayne Simpson (2007). A Panel Multinomial Logit Analysis of Elderly Living Arrangements: Evidence from Aging in Manitoba Longitudinal Data, Canada, Social Science and Medicine. 65: 2539-2552.

Uchino, Bert N., John T. Cacioppo and Janice Kiecolt-Glaser (1996). The Relationship Between Social Support and Physiological Processes: A Review with Emphasis on Underlying Mechanisms and Implications for Health, Psychological Bulletin. 119: 488-531.

Uhlaner, Carole J. (1989). Relational Goods and Participation: Incorporating Sociability into a Theory of Rational Action, Public Choice. 62: 253-285.

Van Dijk, Pieter T., David R. Mehr, Marcel E. Ooms, Richard Madsen, Greg Petroski, Dinnus H. Frijters, Anne Margriet Pot and Miel W. Ribbe (2005). Comorbidity and 1-year Mortality Risks in Nursing Home Residents, Journal of American Geriatric Society. 53: 660-665. 
Table 1. Description of the sample

\begin{tabular}{|c|c|c|c|c|c|c|c|}
\hline \multirow{2}{*}{\multicolumn{3}{|c|}{ Variables }} & \multicolumn{2}{|c|}{ Living conditions } & \multicolumn{2}{|c|}{ Sadness/depression } & \multirow[t]{2}{*}{ All } \\
\hline & & & $\begin{array}{l}\text { Very bad } \\
\text { or Bad }\end{array}$ & $\begin{array}{c}\text { Well or very } \\
\text { well }\end{array}$ & $\begin{array}{l}\text { Always } \\
\text { or often }\end{array}$ & $\begin{array}{c}\text { Sometimes or } \\
\text { never }\end{array}$ & \\
\hline \multicolumn{3}{|c|}{ Female } & 0.773 & 0.762 & 0.819 & 0.768 & 0.763 \\
\hline \multicolumn{3}{|c|}{ Age } & 84.569 & 85.231 & 84.843 & 85.467 & 85.143 \\
\hline \multicolumn{3}{|c|}{ Born in France } & 0.910 & 0.918 & 0.901 & 0.921 & 0.917 \\
\hline \multirow{5}{*}{\multicolumn{2}{|c|}{ Marital status }} & Single & 0.127 & 0.166 & 0.114 & 0.150 & 0.160 \\
\hline & & Married - with spouse & 0.054 & 0.059 & 0.053 & 0.064 & 0.058 \\
\hline & & Married - spouse outside & 0.040 & 0.044 & 0.044 & 0.050 & 0.044 \\
\hline & & Widowed & 0.702 & 0.676 & 0.739 & 0.688 & 0.679 \\
\hline & & Divorced & 0.077 & 0.055 & 0.049 & 0.047 & 0.058 \\
\hline \multicolumn{3}{|c|}{ Number of children } & 2.204 & 1.914 & 2.083 & 1.982 & 1.952 \\
\hline \multirow{6}{*}{\multicolumn{2}{|c|}{ IRG }} & Level1 & 0.090 & 0.070 & 0.077 & 0.079 & 0.073 \\
\hline & & Level2 & 0.311 & 0.229 & 0.290 & 0.272 & 0.240 \\
\hline & & Level3 & 0.177 & 0.140 & 0.174 & 0.154 & 0.145 \\
\hline & & Level 4 & 0.177 & 0.240 & 0.236 & 0.231 & 0.231 \\
\hline & & Level 5 & 0.124 & 0.128 & 0.102 & 0.123 & 0.127 \\
\hline & & Level 6 & 0.120 & 0.193 & 0.120 & 0.141 & 0.183 \\
\hline \multirow[t]{3}{*}{ SAEP } & Retir & ent home & 0.773 & 0.701 & 0.727 & 0.741 & 0.711 \\
\hline & Long & m care units & 0.090 & 0.079 & 0.097 & 0.095 & 0.081 \\
\hline & Shelt & d accommodation & 0.137 & 0.220 & 0.176 & 0.164 & 0.209 \\
\hline \multicolumn{3}{|c|}{ Number of observations } & 299 & 1944 & 568 & 1372 & 2243 \\
\hline
\end{tabular}

Source: 2007 SAEP survey. 
Table 2. Random effects ordered Probit estimates of subjective well-being

A. Living conditions

\begin{tabular}{|c|c|c|c|c|c|c|c|c|c|}
\hline \multicolumn{2}{|l|}{ Variables } & \multicolumn{2}{|c|}{$\begin{array}{l}\text { (1A) All } \\
\text { respondents }\end{array}$} & \multicolumn{2}{|c|}{$\begin{array}{l}\text { (2A) All } \\
\text { respondents }\end{array}$} & \multicolumn{2}{|c|}{$\begin{array}{l}\text { (3A) Proxy } \\
\text { respondents } \\
\text { excluded }\end{array}$} & \multicolumn{2}{|c|}{$\begin{array}{l}\text { (4A) Proxy } \\
\text { respondents } \\
\text { excluded }\end{array}$} \\
\hline \multirow{2}{*}{\multicolumn{2}{|c|}{ Female }} & Coef & t-value & coef & t-value & coef & t-value & coef & t-value \\
\hline & & 0.045 & $(0.67)$ & 0.039 & $(0.58)$ & -0.055 & $(-0.69)$ & -0.038 & $(-0.47)$ \\
\hline \multicolumn{2}{|l|}{ Age } & 0.003 & $(0.76)$ & 0.003 & $(0.81)$ & 0.005 & (1.24) & 0.004 & $(0.91)$ \\
\hline \multicolumn{2}{|l|}{ Born in France } & -0.118 & $(-1.30)$ & -0.111 & $(-1.23)$ & $-0.275^{* *}$ & $(-2.28)$ & $-0.239^{* *}$ & $(-1.98)$ \\
\hline Marital status & Single & $0.138^{*}$ & (1.67) & 0.130 & (1.58) & 0.097 & $(0.99)$ & 0.132 & $(1.35)$ \\
\hline \multirow[t]{3}{*}{ (ref : Widowed) } & Married - with spouse & -0.104 & $(-0.95)$ & -0.073 & $(-0.67)$ & -0.114 & $(-0.88)$ & -0.114 & $(-0.88)$ \\
\hline & Married - spouse outside & 0.023 & $(0.18)$ & 0.041 & $(0.32)$ & 0.002 & $(0.01)$ & -0.003 & $(-0.02)$ \\
\hline & Divorced & 0.070 & $(0.62)$ & 0.053 & $(0.47)$ & 0.140 & $(1.04)$ & 0.152 & $(1.13)$ \\
\hline \multicolumn{2}{|c|}{ Number of children } & -0.018 & $(-1.23)$ & -0.018 & $(-1.22)$ & -0.025 & $(-1.41)$ & -0.025 & $(-1.39)$ \\
\hline \multicolumn{2}{|c|}{ IRG score } & $0.072^{* * *}$ & $(3.60)$ & $0.056^{* * *}$ & $(2.79)$ & $0.087^{* * *}$ & $(3.64)$ & $0.075^{* * *}$ & (3.14) \\
\hline SAEP & Long term care units & -0.090 & $(-0.87)$ & -0.052 & $(-0.52)$ & -0.096 & $(-0.66)$ & -0.109 & $(-0.75)$ \\
\hline (ref : Retir. home) & Sheltered accommodation & $0.343^{* * *}$ & $(4.43)$ & $0.322^{* * *}$ & $(4.26)$ & $0.277^{* * *}$ & (3.03) & $0.259^{* * *}$ & $(2.85)$ \\
\hline \multicolumn{2}{|c|}{ Proxy respondents } & -0.093 & $(-1.47)$ & -0.042 & $(-0.67)$ & & & & \\
\hline \multicolumn{2}{|c|}{ Friends in the nursing home } & & & $0.532^{* * *}$ & $(9.40)$ & $0.639^{* * *}$ & (8.75) & $0.633^{* * *}$ & (8.67) \\
\hline \multicolumn{2}{|c|}{ Visited by family/relatives } & & & & & $0.208^{* *}$ & $(2.17)$ & -0.148 & $(-1.30)$ \\
\hline \multicolumn{2}{|c|}{ Satisfied with frequency of visits from family/relatives } & & & & & & & $0.470^{* * *}$ & $(5.81)$ \\
\hline \multicolumn{2}{|c|}{$\rho$} & 0.080 & & 0.066 & & 0.119 & & 0.114 & \\
\hline \multicolumn{2}{|c|}{ Number of observations } & 2243 & & 2243 & & 1627 & & 1627 & \\
\hline \multicolumn{2}{|c|}{ Number of institutions } & 418 & & 418 & & 400 & & 400 & \\
\hline \multicolumn{2}{|c|}{ Log likelihood } & -2283.9 & & -2239.7 & & -1156.6 & & -1539.7 & \\
\hline \multicolumn{10}{|c|}{ B. Sadness/depression } \\
\hline \multicolumn{2}{|l|}{ Variables } & \multicolumn{2}{|c|}{$\begin{array}{l}\text { (1B) All } \\
\text { respondents }\end{array}$} & \multicolumn{2}{|c|}{$\begin{array}{l}\text { (2B) All } \\
\text { respondents }\end{array}$} & $\begin{array}{l}\text { (3B) Prox } \\
\text { responde } \\
\text { excluded }\end{array}$ & & $\begin{array}{l}\text { (4B) Prox } \\
\text { responde } \\
\text { excluded }\end{array}$ & \\
\hline Female & & $\begin{array}{l}\text { coef } \\
-0.229^{* * *}\end{array}$ & $\begin{array}{l}\text { t-value } \\
(-3.56)\end{array}$ & $\begin{array}{l}\text { coef } \\
-0.234^{* * *}\end{array}$ & $\begin{array}{l}\text { t-value } \\
(-3.63)\end{array}$ & $\begin{array}{l}\text { coef } \\
-0.269^{* * *}\end{array}$ & $\begin{array}{l}\text { t-value } \\
(-3.63)\end{array}$ & $\begin{array}{l}\text { coef } \\
-0.256^{* * *}\end{array}$ & $\begin{array}{l}\text { t-value } \\
(-3.46)\end{array}$ \\
\hline Age & & $0.012^{* * *}$ & (3.74) & $0.012^{* * *}$ & (3.79) & $0.011^{* * *}$ & $(2.73)$ & $0.009^{* *}$ & (2.37) \\
\hline Born in France & & 0.115 & $(1.34)$ & 0.123 & (1.44) & 0.053 & $(0.49)$ & 0.088 & $(0.81)$ \\
\hline Marital status & Single & $0.285^{* * *}$ & (3.63) & $0.282^{* * *}$ & (3.58) & $0.273^{* * *}$ & $(3.00)$ & $0.307^{* * *}$ & (3.38) \\
\hline (ref : Widowed) & Married - with spouse & 0.075 & $(0.72)$ & 0.092 & (0.87) & 0.084 & (0.69) & 0.089 & $(0.74)$ \\
\hline & Married - spouse outside & 0.156 & $(1.28)$ & 0.166 & $(1.36)$ & 0.179 & $(1.12)$ & 0.175 & (1.10) \\
\hline & Divorced & $0.283^{* * *}$ & (2.63) & $0.276^{* *}$ & $(2.56)$ & $0.354^{* * *}$ & $(2.82)$ & $0.370^{* * *}$ & $(2.95)$ \\
\hline Number of childre & & -0.013 & $(-0.87)$ & -0.013 & $(-0.87)$ & -0.018 & $(-1.08)$ & -0.017 & $(-1.01)$ \\
\hline IRG score & & $0.047^{* *}$ & $(2.45)$ & $0.038^{* *}$ & (1.97) & $0.068^{* * *}$ & (3.11) & $0.057^{* * *}$ & $(2.58)$ \\
\hline SAEP & Long term care units & -0.107 & $(-1.13)$ & -0.088 & $(-0.94)$ & -0.035 & $(-0.28)$ & -0.044 & $(-0.36)$ \\
\hline (ref : Retir. home) & Sheltered accommodation & $0.122^{*}$ & (1.77) & 0.110 & (1.61) & 0.089 & (1.18) & 0.069 & $(0.94)$ \\
\hline Proxy respondent & & $-0.245^{* * *}$ & $(-4.04)$ & $-0.220^{* * *}$ & $(-3.61)$ & & & & \\
\hline Friends in the nur & sing home & & & $0.268^{* * *}$ & $(4.95)$ & $0.311^{* * *}$ & $(4.62)$ & $0.302^{* * *}$ & $(4.50)$ \\
\hline Visited by family/r & elatives & & & & & 0.142 & $(1.60)$ & $-0.202^{*}$ & $(-1.91)$ \\
\hline Satisfied with frea & uency of visits from family/relatives & & & & & & & $0.450^{* * *}$ & $(5.99)$ \\
\hline$\rho$ & & 0.043 & & 0.039 & & 0.031 & & 0.022 & \\
\hline Number of observ & ations & 2243 & & 2243 & & 1627 & & 1627 & \\
\hline Number of institu & tions & 418 & & 418 & & 400 & & 400 & \\
\hline Log likelihood & & -2632.6 & & -2620.4 & & -1871.4 & & -1853.5 & \\
\hline
\end{tabular}

Source: 2007 SAEP survey.

Note: estimates from random effect ordered Probit models. Absolute values of $t$ statistics are in brackets, significance levels being equal to $1 \%\left({ }^{* * *}\right), 5 \%\left(\left(^{* *}\right)\right.$ and $10 \%\left({ }^{*}\right)$. Each regression also includes a set of six occupational dummies. 
Table 3. Random effect ordered Probit estimates of changes in living conditions

\begin{tabular}{lllll}
\hline Variables & \multicolumn{2}{l}{ (1) All respondents } & \multicolumn{2}{l}{ (2) Proxy respondents excluded } \\
\hline & coef & t-test & coef & t-test \\
Female & 0.035 & $(0.59)$ & 0.055 & $(0.80)$ \\
Age & -0.005 & $(-1.57)$ & -0.003 & $(-0.82)$ \\
Years in retirement home & $-0.015^{* * *}$ & $(-3.18)$ & $-0.015^{* * *}$ & $(-2.80)$ \\
IRG score & -0.004 & $(-0.24)$ & 0.009 & $(0.41)$ \\
Proxy respondents & -0.051 & $(-0.80)$ & & $(2.30)$ \\
Friends in the nursing home & $0.130^{* *}$ & $(2.30)$ & $0.164^{* *}$ & 0.098 \\
\hline$\rho$ & 0.077 & & 1596 & \\
\hline Number of observations & 2176 & & 400 & \\
Number of institutions & 418 & & -1645.3 & \\
Log likelihood & -2406.9 & & & \\
\hline
\end{tabular}

Source: 2007 SAEP survey.

Note: estimates from random effect ordered Probit models. Absolute values of $t$ statistics are in brackets, significance levels being equal to $1 \%\left({ }^{* * *}\right), 5 \%\left({ }^{* *}\right)$ and $10 \%\left({ }^{*}\right)$. 
Figure 1.Initial and current living conditions of respondents

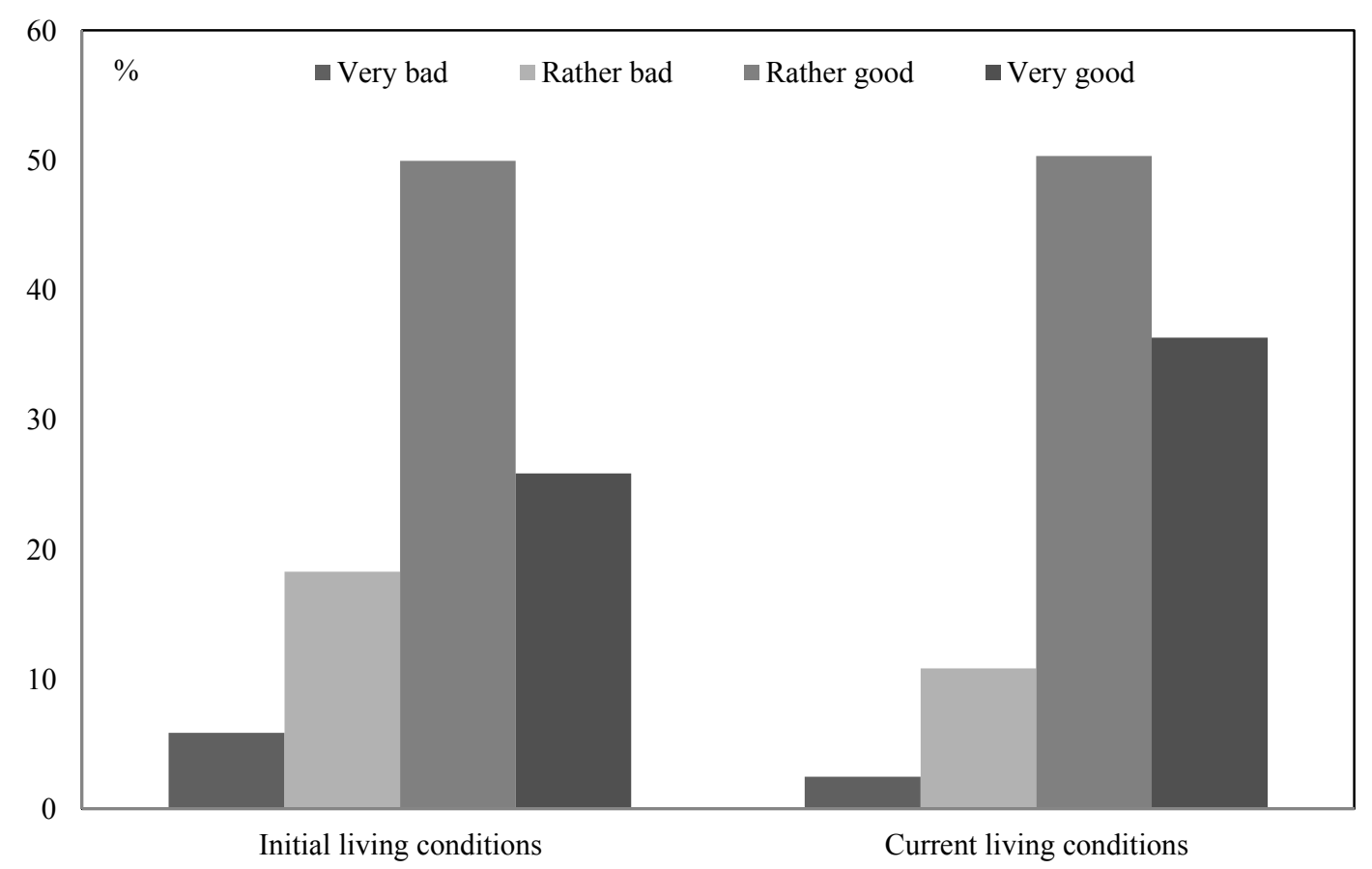

Source: 2007 SAEP Survey. 
Figure 2. Subjective well-being of respondents and friends A. Living conditions

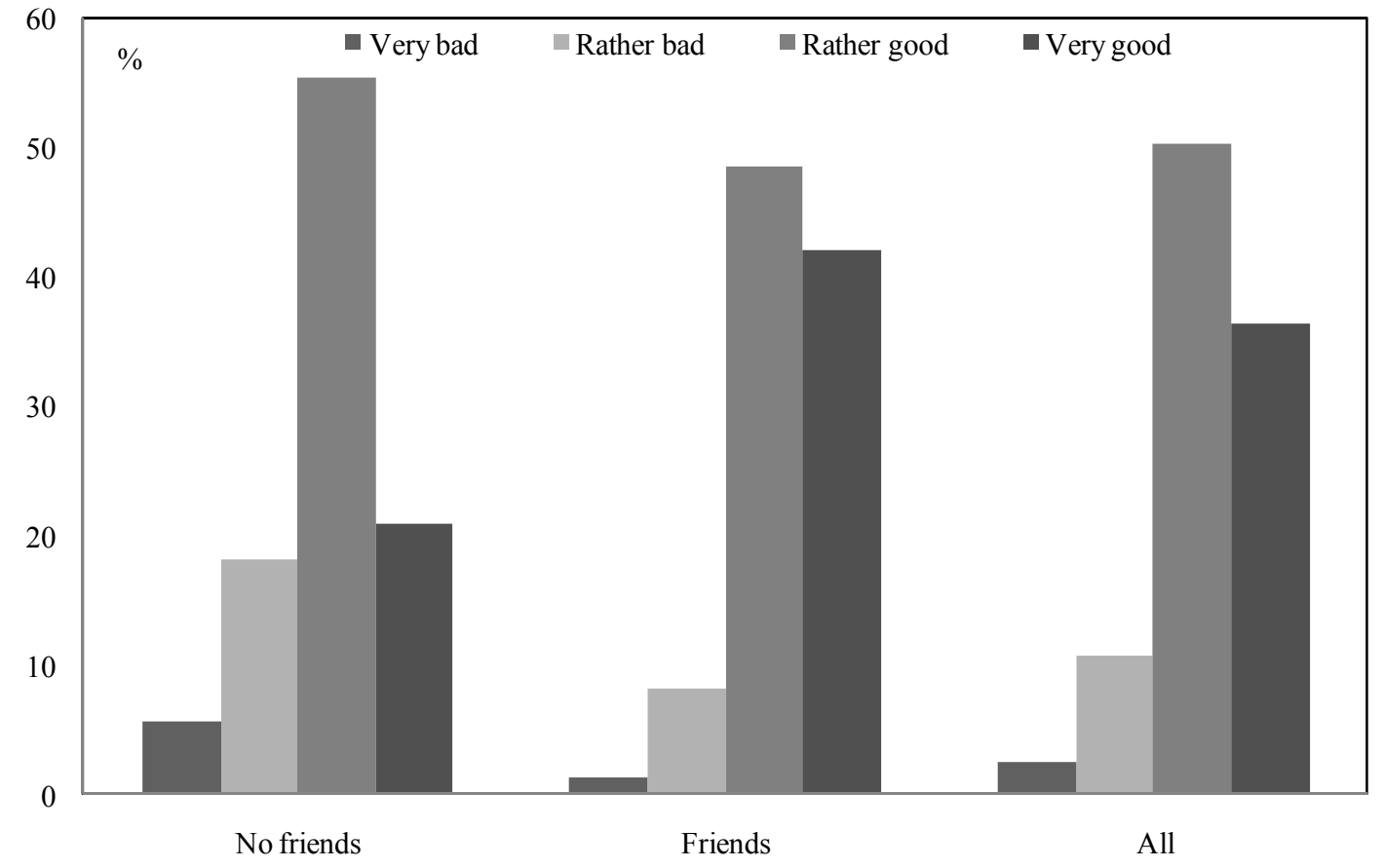

B. Sadness/depression

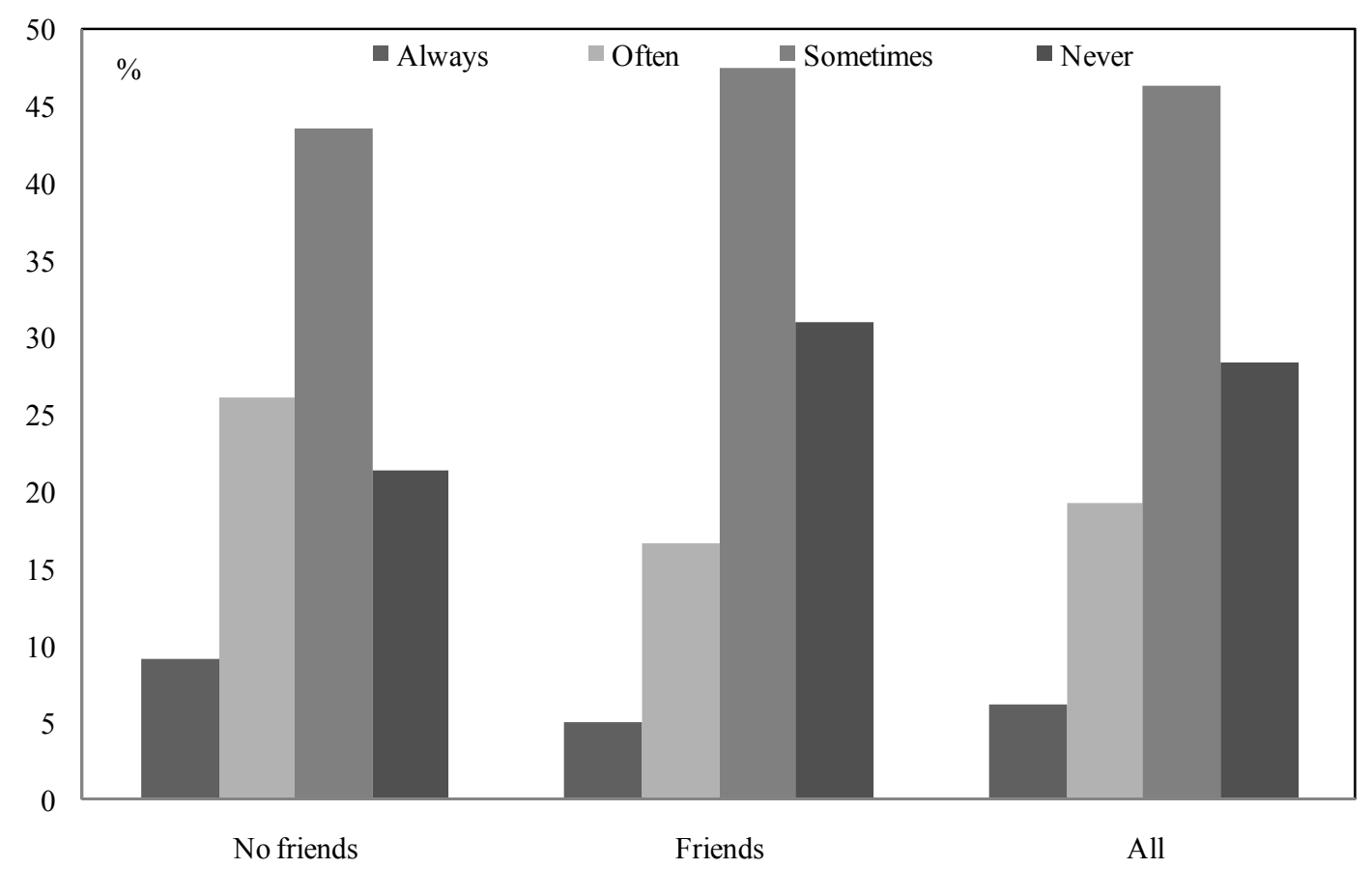

Source: 2007 SAEP Survey. 


\title{
Well-being of elderly people living in nursing homes: The benefits of making friends $\#$
}

\author{
François-Charles Wolff
}

September 2012

\begin{abstract}
Using French data collected in 2007 from a sample of about 2,000 elderly people living in nursing homes, this paper investigates the role that individual characteristics play in satisfaction with life and depression. Following psychological studies that have highlighted the benefits of social interactions on individual well-being, I focus in particular on the role played by making friends in the nursing home. Results from random effect ordered Probit models show that both satisfaction with living conditions and feeling of depression are much more influenced by making friends in the institution than by visits from family and relatives or other individual background characteristics. These findings may be interpreted as evidence of a relational return to friendship within nursing homes.
\end{abstract}

Keywords: friends, institutionalized elderly, living conditions, nursing home, relational goods

\footnotetext{
\# I would like to thank anonymous reviewers for their very hepful comments and suggestions on a previous draft. The usual disclaimer applies.

${ }^{*}$ Corresponding author. LEMNA, Université de Nantes, BP 52231 Chemin de la Censive du Tertre, 44322 Nantes Cedex 3 , France and INED, Paris, France.

E-mail: francois.wolff@univ-nantes.fr http://www.sc-eco.univ-nantes.fr/ fcwolff
} 


\section{Introduction}

The rapidly ageing worldwide population is creating a number of challenges for both developed and developing countries. According to the World Health Organization, this includes among others strains on social security systems and pensions, increasing demand for health care and rising needs for long-term care programs. Over the last few years, a number of studies have been conducted to identify factors associated to entry and living in institutions.

Entry into a nursing home strongly increases with age, especially among the oldest elderly. Women, married and healthy people are less likely to be institutionalized (Ness et al., 2004, Sarma and Simpson, 2007) ${ }^{1}$. Publicly provided home care and access to informal care affect living arrangement decisions. For instance, elderly with a greater number of living children enter a nursing homeless often (Jette et al., 1995). Significant differences have been reported between nursing home and community-residing elderly people, for instance in mortality risk (Van Dijk et al., 2005), health status (Asakawa et al., 2009), quality of life and well-being (McAuley et al., 2000, Gueldner et al., 2001, Borowiak and Kostka, 2004, Borg et al., 2006, Onishi et al., 2010).

With the increasing number of individuals in long-term care, a challenging policy objective consists of effectively managing elderly people's quality of life. Understanding factors associated with quality of life and life satisfaction of the institutionalized elderly is hence an important issue that has notably been under-investigated so far. Nowadays, nursing homes not only concentrate on prevention and treatment of chronic diseases and illnesses affecting the elderly, they also take into consideration the quality of life and life satisfaction of their own residents.

The specific purpose of my contribution is to examine the role of individual characteristics that contribute to life satisfaction and depression in nursing homes. My empirical analysis draws on data collected in France as this country is likely to experience one of the strongest increases in its retirement home population (Jacobzone et al., 2001). The situation of residents in retirement homes in France and especially their life satisfaction is poorly documented, which may be explained by the exclusion of institutionalized elderly from standard household surveys ${ }^{2}$. I focus in particular on the role played by social relationships and more precisely friends in the nursing home.

Several psychological studies have highlighted the benefits of social interactions on individual well-being, a mechanism called social resources by Musick and Wilson (2003). Following Baumeister and Leary (1995, p. 497), "human beings have a pervasive drive to form and maintain at least a minimum quantity of lasting, positive and significant interpersonal relationships". Social support has beneficial effects on a large set of physical health outcomes (Uchino et al., 1996), while social

\footnotetext{
${ }^{1}$ See Miller and Weissert (2000) for an overview of the predictors of institutionalization.

${ }^{2}$ In 1998, about 480,000 people over 60 were in retirement homes or long-term care facilities and most residents were satisfied with their accommodation (Dufour-Kippelen and Mesrine, 2003).
} 
isolation is depressing (Mirowsky and Ross, 1989). The reduction in social contact has been proved an important predictor of cognitive decline (Penninx, 1997).

A few economists have also argued that interpersonal contact matters in its own right (Kolm, 2000, Gui, 2000). This refers to the concept of relational goods, which may be seen as intangible outputs produced through interactions (Uhlaner, 1989). Both in France and in Italy, Prouteau and Wolff (2004) and Degli Antoni (2009) find that people volunteer in order to increase their social network, especially for intrinsically motivated volunteers. Using data from Germany, Becchetti et al. (2008) show that activities producing relational goods have significant and positive effects on selfassessed life satisfaction. The effect of sociability on happiness tends to be stronger for women, older and less educated people.

In what follows, I hypothesize that the benefits of social interactions that people have with others and especially with friends should be large among institutionalized elderly. To assess the causal benefit of making friends in the institution, I consider a French survey conducted in 2007 on a sample of about 2,000 elderly people living in retirement homes or long-term care units. For each respondent, the questionnaire includes ordered indicators on the well-being in the institution and on the feeling of sadness or depression. It also indicates whether the respondent has made any friends in the institution. As the data includes several residents per nursing home, I estimate random effect ordered Probit models to study the role of individual characteristics on well-being.

My main results are that both satisfaction with living conditions and feelings of sadness or depression are much more influenced by making friends in the institution than by visits from family and relatives. This pattern is robust to problems of measurement error, unobserved heterogeneity and simultaneity. The remainder of my paper is organized as follows. In Section 2, I describe the data and living conditions of elderly people living in institutions in France. Section 3 investigates the determinants of subjective well-being among elderly residents and provides several robustness checks related to endogeneity issues. Section 4 concludes.

\section{Data and descriptive statistics}

\section{II.1. The SAEP survey}

I study the well-being of elderly people living in institutions using a survey conducted in France by the Direction of Research, Studies, Evaluation and Statistics (DRESS) in 2007. This survey entitled "Residents in Sheltered Accommodation for Elderly People" (SAEP hereafter) concerns a representative sample of respondents living either in traditional retirement homes, in retirement homes for dependent elderly people, in sheltered accommodation or in long-term care units. Its main purpose was to describe both the entry and the current living conditions of residents in SAEP 
and to assess the quality of their care in these institutions. The sample of the SAEP survey was constructed in the following way.

First, information was collected from 433 institutions about their own residents. For each institution, a random sample of eight residents was selected to take part in the SAEP survey. Both institution heads and nursing staff had to assess whether these residents were able or not to answer the questionnaire by themselves. The staff had also to give the address and details of a person close to the resident, defined as "someone who knows the resident well, has good relations with him/her and visits him/her regularly". Among the 3,464 potential residents, 1,802 were directly interviewed and 2,066 proxy respondents were interviewed, either in place of or in addition to the resident. The SAEP survey comprises 2,742 observations, with 1,126 questionnaires in duplicate (completed by both the resident and the proxy respondent).

I rely on the following ordered indicators to study the well-being of elderly people living in a care-giving institution. The first question is about current living conditions: "how is your life in this institution?". Possible answers are "very bad", "rather bad", "rather good", "very good". I also know how the resident felt about his/her first moments spent in the institution, with the same set of outcomes ranging from "very bad" to "very good". The second question is about sadness and depression: "do you feel sad, distressed or depressed?". Possible answers are "always", "often", "sometimes", "never". In both cases, similar questions were asked to the proxy respondent on behalf of the resident.

I considered the following individual characteristics to explain the well-being indicators: gender, age, born in France, marital status, number of children, last occupation if any (a proxy for socio-economic status), and health which is expected to have a strong influence on living conditions during old age. As self-assessed measures of health are likely to be contaminated by subjectivity bias, I consider a more objective indicator describing the state of dependency of each resident. The IsoResources Group (IRG) outcome is assessed by a medico-social team and relies on a set of discriminatory factors regarding the loss of physical and psychological independence like orientation or coherence. Each resident is classified into one of six groups depending on loss of independence ${ }^{3}$.

As I am interested in the role of social relationships on well-being, I constructed a dummy variable which is equal to one when the respondent has made friends with the other residents and zero otherwise. This information is provided both by residents who were directly interviewed and by proxy respondents when residents were not in a position to fill in the questionnaire by themselves.

\footnotetext{
${ }^{3}$ Group 1 corresponds to people who are bed-ridden or chair-ridden and have lost their mental and physical independence. Group 2 includes people who are bed-ridden or chair-ridden and require assistance with daily activities, but whose mental capacity is not completely affected. It also comprises people who are able-bodied, but whose mental capacity is affected. People in group 3 are mentally autonomous, but require assistance with their physical autonomy, daily and several times per day. People in group 4 can move inside the accommodation after rising, but need help washing and dressing themselves. Finally, people from group 5 and 6 are respectively very slightly and not at all dependent.
} 
Another question is about whether the resident receives visits from relatives, but this question was not asked to proxy respondents ${ }^{4}$. I again constructed a dummy variable when the respondent reported such visits. Residents further indicated whether the frequency of these visits was right for them or whether they would have appreciated receiving more visits from relatives. In what follows, I will study the effect of these social relationships on the well-being of residents.

I restricted the sample in the following way. I deleted respondents younger than 60 years $(\mathrm{N}=42)$ and observations with unknown IRG score $(\mathrm{N}=119)$. I also excluded residents or proxy respondents who did not provide information on living conditions and depression ( $N=338)$. This left me with a sample of 2,243 residents belonging to 418 SAEP. The mean number of residents with complete questionnaire data is 5.4 per SAEP.

\section{II.2. Living conditions in French institutions}

According to the SAEP survey, elderly people in French institutions were on average satisfied or very satisfied with their current living conditions. One-half of them claimed that they lived rather well and $36.3 \%$ that they lived very well. The proportion of unsatisfied residents is $13.3 \%$, a very small proportion (2.5\%) living very badly in their institution. The same pattern is found for the sadness/depression indicator. About one-quarter of residents always (6.1\%) or often (19.2\%) felt sad, distressed or depressed, while $28.4 \%$ did not have such feelings. I found that about $70 \%$ of respondents both lived well or very well and were sometimes or never sad/depressed.

It is interesting to compare the well-being of nursing home people to the general population. Drawing on the Eurobarometer surveys, Afsa and Marcus (2008) show that the proportion of respondents being either very or rather satisfied with their life (whatever their age) was between 70\% and 80\% from 1975 to 2000 in France. I find a slightly higher proportion of residents living well in nursing home (around $85 \%$ ), but satisfaction with living conditions and satisfaction with life satisfaction may sound like different concepts for residents. When taking age into account, Afsa and Marcus (2008) show that life satisfaction strongly reduces after 68 years old. Using data collected in 2010, Godefroy (2011) finds a very similar pattern. In particular, people aged above 80 years old have much lower levels of satisfaction on average.

In Figure 1, I present the pattern of both living conditions when entering the nursing home and current living conditions. Residents are on average more satisfied now with their living conditions than during the first moments after their admission to a home. There are many more residents living very well now than after entry (36.3\% compared to $25.9 \%$ ). When crossing both measures, simple calculations show that life satisfaction remains unchanged for $58.4 \%$ of residents,

\footnotetext{
${ }^{4}$ By definition, proxy respondents are relatives of the non-interviewed resident. $95 \%$ of them are members of the family and $69 \%$ are children of the residents.
} 
while it improves more frequently than it worsens (respectively $31.4 \%$ and $10.2 \%$ ). Several explanations may come to mind to explain this pattern.

\section{Insert Figure 1}

As age increases, being placed in a nursing home is a hard decision to take as nursing homes are often seen as being the stopover point prior to death. Elderly people could thus be apprehensive especially if they have the feeling they are losing part of their independence by leaving their own home. At the same time, people are often placed in nursing homes when their ageing process is affected by several illnesses and medical conditions. Due to this selection effect, their well-being is likely to improve once they are receiving the quality of care they deserve. After a while, living in a nursing home may also offer new perspectives for residents. Many nursing home facilities offer residents a full range of activities and elderly people could be happy to be involved in these activities. In particular, this may offer opportunities to make friends in the home.

I describe the relationship between subjective well-being and making friends in Figure 2 . The SAEP data shows a positive correlation between having made friends in the institution and wellbeing. The proportion of respondents claiming that they live very well in their nursing home is $42.1 \%$ when residents have made friends, but only $20.9 \%$ otherwise. Residents are much more likely to live badly or very badly when they have no friends, $23.7 \%$ instead of $9.5 \%$. The same pattern is found for sadness/depression. The gap between residents with and without friends remains large, $30.1 \%$ compared to $20.4 \%$. Interestingly, the influence of friends on well-being seems much larger than that of visits from family. On the basis of statements from directly interviewed residents, I find that the proportion of residents living very well is only six points higher among those receiving visits from family members (37.4\% instead of $31 \%)$. Besides, the proportion of residents being always or often sad or distressed is nearly the same with or without family visits.

Insert Figure 2

The positive correlation between making friends and subjective well-being supports several interpretations. On the one hand, there may be a relational return to friendship, so that residents would themselves feel better when they have friends to share all of life's ups and downs. On the other hand, the positive correlation may be due to heterogeneity in individual characteristics. If there are factors that influence both the determinants of living conditions and having friends, then the positive relation between these outcomes could be spurious. For instance, residents in better health should on average live better than those in poor health. At the same time, they are certainly more likely to make friends by taking part in guided activities offered in the nursing home.

A description of the sample shows the need to account for heterogeneity when explaining subjective well-being among elderly nursing home residents. According to Table 1, residents living well or very well are slightly older. They are on average in better health and are over-represented in 
sheltered accommodation. Residents who are sometimes or never concerned by sadness or depression are more often women or single. They have lower IRG scores than depressed residents, while the type of SAEP plays no role. It is hence important to account for individual characteristics when explaining subjective well-being of elderly people living in nursing homes.

Insert Table 1

\section{The determinants of subjective well-being among elderly residents}

\section{III.1. Econometric specification}

I rely on an econometric analysis to study the relationship between well-being and making friends. Two sets of factors are expected to influence living conditions of nursing home resident elderly: individual characteristics and the specific features of the nursing home. In what follows, I draw on panel data techniques to account for both unobserved and observed characteristics of institutions. I simply exploit the fact that the SAEP survey includes data on several residents per nursing home.

For the presentation, let $W^{k}$ be an indicator of well-being, respectively living conditions $(k=L C)$ and sadness/depression $(k=S D)$, such that $W^{L C}=1$ when the resident lives "very badly", $W^{L C}=2$ when "badly", $W^{L C}=3$ when "well", and $W^{L C}=4$ when "very well". Similarly, $W^{S D}$ ranges from 1 when the resident is always sad/depressed to 4 when this is never the case. Let $W^{k *}$ be two latent variables associated to these subjective indicators $(k=L C, S D)$. I assume that $W^{k *} \leq \mu_{1}^{k}$ when $W^{k}=1, \mu_{1}^{k}<W^{k *} \leq \mu_{2}^{k}$ when $W^{k}=2, \mu_{2}^{k}<W^{k *} \leq \mu_{3}^{k}$ when $W^{k}=3$, and $\mu_{3}^{k}<W^{k *}$ when $W^{k}=4$. I consider a linear expression for the latent outcome:

$$
W_{j i}^{k *}=X_{j i} \beta+\theta F_{j i}+\delta_{j}+\varepsilon_{j i}
$$

where $j$ and $i$ as subscripts refer respectively to the nursing home and to the resident, $X$ is a set of individual characteristics, $F$ is a dummy indicating whether the resident has made friends in the institution, $\beta$ and $\theta$ are parameters to estimate, and $\delta$ and $\varepsilon$ are error terms. In (1), $\delta_{j}$ is an unobserved nursing home effect. It will, for instance, pick up the various facilities at the disposal of residents inside the institution, adequateness of the staff including size of the nursing staff, presence of a dietician, occupational therapist or recreational advisor, activities the facility encourages the residents to be part of, the possibility of having safe and comfortable rooms, the fact that residents may be allowed to move in furniture items from their own home, the type of food served, etc.

I suppose that $\delta_{j} \sim N\left(0 ; \sigma_{\delta}^{2}\right)$ and $\varepsilon_{j i} \sim N(0 ; 1)$. Under the assumption that the individual characteristics are uncorrelated with the nursing home effects, (1) defines a random effect ordered Probit model. This implies that the different threshold levels $\mu^{k}$ have to be estimated jointly with the 
parameters of interest $\beta$ and $\theta$. Since the likelihood function involves multivariate normal integrals, the ordered Probit model is estimated using quadrature techniques (Butler and Moffit, 1982).

\section{III.2. Random effect estimates of subjective well-being}

Table 2 presents the random effect ordered estimates respectively for living conditions (part A) and sadness/depression (part B), higher scores being associated with higher subjective wellbeing ${ }^{5}$. Let me first consider living conditions. According to the estimates, it appears somewhat difficult to explain whether residents live well or badly in their current location on the basis of their individual characteristics. Gender, age, place of birth and number of children do not matter (column 1A). Single residents live slightly better, but the relationship is hardly significant. The most influential predictor of living conditions is the IRG score. Not surprisingly, those who are in better health claim that they live better on average.

\section{Insert Table 2 here}

Residents living in sheltered accommodation are also better off, which could be evidence of some selection effect. Less well off elderly people are more likely to be placed in retirement homes or in long term care units, while sheltered accommodation is more designed to be an intermediate step between the resident's original home and a traditional retirement home. It will appeal to old people who are able-bodied, but are no longer able to (or do not want to) live by themselves. Finally, answers about living conditions are not different when being provided by the residents themselves or by proxy respondents.

In column (2A), I introduce the presence of friends in the different environments. I find a large positive correlation between having friends and living conditions. Doing as if the dependent variable were continuous, random effect least square estimates indicate that living conditions improve by $33.4 \%$ when residents have made friends in their new place of residence. This is simply the most influential covariate when explaining living conditions, far beyond the other explanatory variables. For the sake of comparison, I investigate the role of visits from family members and relatives. As, by definition, such visits exist in the case of proxy respondents, I only consider the subsample of residents answering the questionnaire by themselves.

Receiving visits from family and relatives also significantly improves well-being (column 3A). However, the coefficient associated to having friends is much higher than that of the family and

\footnotetext{
${ }^{5}$ In both cases, there is little variation in the mean level of well-being of residents between the various nursing homes. The ratio $\rho=\sigma_{\delta}^{2} /\left(1+\sigma_{\delta}^{2}\right)$ ranges from 0.02 to 0.11 , meaning that the within unexplained variance $\sigma_{\delta}^{2}$ is much lower than 1 . There are hence large unexplained variations in subjective well-being between residents living in a given nursing home in France.
} 
relatives ${ }^{6}$. Results from random effect linear models show that the marginal effect of family visits (11.3\%) is more than three times lower than that of having friends. Residents further indicate whether they are satisfied or not with the frequency of visits from family or relatives. I find that residents claim living better only when they are satisfied with the frequency of family visits. When they are not satisfied, their level of well-being tends to be slightly lower (column 4A).

I then investigate sadness and depression determinants (part B, Table 2). On average, women are more often sad or depressed than men (column 1B). Older, single and divorced residents are less subject to sadness/depression, while having children has no influence. Those being in better physical health (measured by the IRG score) are also less affected by mental difficulties. Contrary to what was observed for living conditions, there is no difference in mental health by type of institutions while the presence of proxy respondents is now significant. Proxy respondents are less optimistic about the well-being of the residents as they assess the latter as more often distressed or depressed.

I add in column (2B) the dummy variable associated to friends. As observed for living conditions, having friends within the nursing home significantly improves the feeling of not being sad or depressed. Estimates from a random effect linear model suggest that not having friends increases the propensity for feeling sad or depressed by about $20 \%$. At first viewing, sadness and depression are not affected by visits received by family and relatives among self-interviewed residents (column 3B). Nevertheless, a more accurate look at the data shows that there is a significant relationship between these visits and sadness/depression only when residents are satisfied with the frequency of visits. When they are not satisfied, residents feel sad or depressed more often, which could be due to the frustration of not having enough contact with family and relatives.

\section{III.3. Endogeneity issues}

The ordered estimates suggest that having friends in the nursing home has a beneficial effect on the subjective well-being of institutionalized elderly. With respect to the previous regressions, a question worth is to know whether the dummy variable associated to friends can really be treated as exogenous. Endogeneity may be due to one of the following reasons: measurement errors, unobserved heterogeneity and simultaneity.

Let me first focus on measurement errors. The main difficulty lies with the presence of proxy respondents, as the latter may have a less accurate perception of the resident's situation. Spending a long time in the institution is needed for proxy respondents to know whether residents have made friends or not, but a correct assessment of their living conditions may still be uneasy without sharing their daily activities or meals. Interestingly, the SAEP data shed light on the divergence in answers

\footnotetext{
${ }^{6}$ A Wald test indicates that the two coefficients are significantly different. I obtain a value of 86.6 for the corresponding statistic, with 1 degree of freedom.
} 
that may occur because of proxy respondents. By definition, I have questionnaires completed by both the resident and a proxy respondent in 1,039 cases. When comparing their answers, I observe substantial differences for several outcomes.

Among directly interviewed residents, $78.7 \%$ of them report having friends in the home. This proportion is more than four percent higher (83.1\%) according to proxy respondents. However, the corresponding crossed table shows that the proportion of concordant answers is around $76 \%$. So, measurement errors occur in about one case over four when drawing on information provided by proxy respondents instead of answers from residents themselves. The situation is even worse for the indicator of living conditions since only $53.4 \%$ of answers are similar. Nevertheless, differences remain tenuous as they essentially concern whether residents live well or very well?.

A solution to the problem set by measurement errors consists in excluding the cases with proxy respondents, which is done in columns (1A), (2A), (1B) and (2B) of Table 2. In these random effect regressions, I obtain a large marginal effect of friends on well-being. At the same time, this leads to sample selection since residents in poor or very poor health are less likely to be interviewed. Estimates in columns $(3 \mathrm{~A})$ and $(3 \mathrm{~B})$ have then to be seen as upper bounds since they will pick up the returns of making friends among the healthiest nursing home residents. To further highlight this result, $I$ introduce an additional crossed term in (2A) and (2B) which is equal to one when the resident has friends and answers are provided by proxy respondents. In both cases, I find significant values for the crossed term (at $10 \%$ for sadness/depression), meaning that the marginal effect of making friends is lower when the resident is unable to answer to the questionnaire by himself/herself ${ }^{8}$.

The second concern is about omitted variables. Although the random effect regressions account for unobserved heterogeneity, these specifications may lead to biased estimates if the institution effects are correlated with the explanatory variables. This could occur for instance if residents locate in specific institutions depending on their health status. I have thus also considered a fixed effect framework, drawing on the conditional estimator proposed in Das and Van Soest (1999) These estimates, not reported, show that my previous findings remain valid with the fixed effect specification.

I find that within nursing homes, residents having made friends live much better on average. After excluding proxy respondents, living conditions are positively correlated with visits from family

\footnotetext{
${ }^{7} 16.8 \%$ of residents claim that they live very well while proxy respondents believe they live well. In the same way, $13.1 \%$ of residents claim to live well when proxy respondents think they live very well.

${ }^{8}$ These additional results are available upon request. For living conditions, the coefficient associated to the crossed term is equal to -0.284 ( $t=-2.44)$ while the coefficient associated to having friends is 0.631 .

${ }^{9}$ In a first step, I estimate a set of fixed effect Logit models by grouping together adjacent outcomes related respectively to living conditions or sadness/depression. Then, I rely on a classical minimum distance estimator. Results from the ordered fixed effect regressions are available upon request.
} 
and relatives, but the corresponding marginal effect is twice as low as that of friends. Making friends also reduces the feeling of being sad or depressed. Further, I find that answers from proxy respondents strongly reduce the propensity of not being sad or depressed. This is evidence that proxy respondents tend to have a more pessimistic view on the psychological difficulties of residents than the latter have.

The last issue that could lead to endogeneity bias is simultaneity. In particular, reverse causality could explain the positive correlation between making friends and current living conditions if elderly people living well make friends more easily. Residents smiling and feeling happy when entering the nursing home will certainly be perceived as more attractive by other residents, which would increase the likelihood of establishing friendly relationships. The survey allows me to further study the relevance of these two competing interpretations, i.e. having friends increases the subjective well-being of residents versus residents living better make friends more easily.

In the SAEP survey, residents are asked about their living conditions just after entering the institution. This initial state is unlikely to be contaminated by the impact of making friends in the nursing home. As a consequence, I account for the fact that more well-off elderly people could make friends more easily by adding their initial state of living conditions into the regression. I first reestimate the random effect ordered Probit regression on the subsample of 2,176 residents with information on both current and initial living conditions. I find a coefficient equal to 0.550 ( $t=9.52)$ for the friends dummy, which is very close to the estimate reported in column (2A) of Table 2. Then, I add initial living conditions in the regression. These estimates, available upon request, leads to the two following results.

First, I find that assessment about living conditions when entering the nursing home strongly influences current living conditions (state dependence). Secondly, I get a slightly lower coefficient for the friends dummy (0.439 instead of 0.550$)$, but the covariate remains highly significant $(t=7.35)$. From random effect linear estimates, this would correspond to a fall of $28.5 \%$ in the return of having friends on current living conditions (from $34.7 \%$ to $24.8 \%$ ). The fall is even slightly higher (31.1\%) when excluding proxy respondents from the sample. Having friends in the institution increases the indicator of living conditions when initial living conditions are taken into account by $27.2 \%$ (instead of $39.5 \%$ without initial living conditions). These results suggest that residents living better when entering the nursing home make friends more easily after a while.

However, the positive effect of making friends still remains. I further investigate the dynamics in living conditions by estimating the difference between current and initial living conditions as a function of individual characteristics and having friends. If my interpretation in terms of social relationships is correct, then I should observe that having made friends during the stay in nursing home has, on average, improved living conditions among residents. As there are very few 
extreme values, I recode the dependent variable defined as the difference between initial current and living conditions so that it ranges from -2 to $2^{10}$.

Residents with a positive value (31.4\%) live better in the nursing home now than just after their entry. Since the dependent variable is ordered, I again turn to ordered Probit models and account for unobserved heterogeneity at the institution level using random effect models ${ }^{11}$. Given my previous results, I rely on a small number of covariates and consider the following covariates: gender, age, IRG score, years in the retirement home, questionnaire completed by a proxy respondent and making friends.

As shown in Table 3, I find that years spent in the retirement home are negatively related to changes in well-being, while other individual characteristics do not matter. Residents who have made friends in the nursing home report more often improved living conditions according to the random effect estimates (column 1). Excluding proxy respondents from the sample does not affect this conclusion (column 2), making friends remaining significant at the five percent level.

\section{Insert Table 3}

\section{Conclusion}

According to demographic projections, the number of elderly people living in retirement or nursing homes should strongly increase in many developed countries over the coming years. While this phenomenon will put a strong pressure on the number of places available in nursing homes, another issue that deserves researchers' attention is the quality of life and well-being of institutionalized elderly as it has an impact on both their physical and mental health. In this paper, I have used recently collected data from France to investigate the factors influencing life satisfaction and depression of elderly people living in retirement homes or long-term care units.

Following psychological studies that have highlighted the benefits of social interactions on individual well-being, I have put emphasis on the role played by making friends in nursing home. My main results are that both satisfaction with living conditions and feelings of sadness or depression are much more influenced by making friends in the institution than by visits from family and relatives or by any other individual background characteristics. These findings, which are robust to problems of measurement errors, unobserved heterogeneity and simultaneity, may be interpreted as evidence of a relational return to friendship within nursing homes.

From a public policy viewpoint, my results suggest that the quality of life of retirement or nursing home residents could be improved using simple solutions. For instance, promoting very

\footnotetext{
${ }^{10}$ According to the data, six residents are characterized by a difference of -3 and 16 by a difference of 3 . The proportion of residents with a difference of -2 is $2.2 \%, 10.2 \%$ for $-1,58.4 \%$ for $0,25.6 \%$ for 1 and $5.8 \%$ for 2 .

${ }^{11}$ I have also estimated fixed effect regressions. These estimates (available upon request) show that making friends in the institution improves assessment on living conditions only among residents who were directly interviewed.
} 
regularly social or recreational activities that allow frequent meetings and interactions between residents, including those recently entered into the nursing home, is likely to enhance interpersonal relationships and friendship without requiring too many additional expenditures from the nursing staff. These are undoubtedly opportunities of interest in a context where developed countries have to deal with the challenging burden of increasing spending on long term care due to the ageing of their populations. 


\section{References}

Afsa, Cédric and Vincent Marcus (2008). Le Bonheur Attend-Il le Nombre des Années ?, in: INSEE, France, Portrait Social. Insee Références: 163-174.

Asakawa, Keiko, David Feeny, Ambikaipakan Senthilselvan, Jeffrey A. Johnson and Darryl Rolfson (2009). Do the Determinants of Health Differ Between People Living in the Community and in Institutions ?, Social Science and Medicine. 69: 345-353.

Baumeister, Roy F. and Mark R. Leary (1995). The Need to Belong : Desire for Interpersonal Attachment as a Fundamental Human Motivation, Psychological Bulletin. 117: 497-529.

Becchetti, Leonardo, Alessandra Pelloni and Fiammetta Rossetti (2008). Relational Goods, Sociability and Happiness, Kyklos. 61: 343-363.

Borg, Christel, Ingalill R. Hallbergl. and Kerstin Blomqvist (2006). Life Satisfaction among Older People (65+) with Reduced Self-Care Capacity: The Relationship to Social, Health and Financial Aspects, Journal of Clinical Nursing. 15: 607-618.

Borowiak, Ewa and Tomasz Kostka (2004). Predictors of Quality of Life in Older People Living at Home and Institutions, Aging Clinical and Experimental Research. 16: 212-220.

Butler, J.S. and Robert Moffitt (1982). A Computationally Efficient Quadrature Procedure for the OneFactor Multinomial Probit Model, Econometrica. 50: 761-764.

Chamberlain, Gary (1980). Analysis of Covariance with Qualitative Data, Review of Economic Studies. 47: 225-238.

Das, Marcel and Arthur van Soest (1999). A Panel Data Model for Subjective Information on Household Income Growth, Journal of Economic Behavior and Organization. 40: 409-426.

Degli Antoni, Giacomo (2009). Intrinsic vs. Extrinsic Motivations to Volunteer and Social Capital Formation, Kyklos. 62: 359-370.

Dufour-Kippelen, Sandrine and Annie Mesrine (2003). Les Personnes Agées en Institution, Revue Française des Affaires sociales. 1: 123-148.

Godefroy, Pascal (2011). Satisfaction dans la Vie: Les Personnes se Donnent 7 sur 10 en Moyenne, in: INSEE, France, Portrait Social. Insee Références: 105-118.

Gueldner, Sarah H., Susan Loeb, Diana Morris, Janice Penrod, Martha Bramlett, Linda Johnston and Patricia Schlotzhauer (2001). A Comparison of Life Satisfaction and Mood in Nursing Home Residents and Community-Dwelling Elders, Archives of Psychiatric Nursing. 15: 232-240.

Gui, Benedetto (2000). Beyond Transactions: On the Interpersonal Dimension of Economic Reality, Annals of Public and Cooperative Economics. 71: 139-169.

Jacobzone, Stephane, Emmanuelle Cambois and Jean-Marie Robine (2000). Is the Health of Older Persons in OECD Countries Improving Fast Enough to Compensate for Population Ageing?, OECD Economic Studies. 30: 149-190.

Jette, Alan M., Sharon Tennstedt and Sybil Crawford (1995). How Does Formal and Informal Community Care Affect Nursing Home Use?, Journal of Gerontology. 50: S4-S12.

Kolm, Serge-Christophe (2000). The Theory of Reciprocity, in: Louis-André Gérard-Varet, SergeChristophe Kolm and Jean Mercier-Ythier (eds.), The Economics of Reciprocity, Giving and Altruism. MacMillan Press: 115-141.

McAuley, Edward, Bryan Blissmer, David X. Marquez, Gerald J. Jerome, Arthur F. Kramer and Jeffrey Katula (2000). Social Relations, Physical Activity, and Well-Being in Older Adults, Preventive Medicine. 31: 608-617. 
Meier, Stephan and Alois Stutzer (2008). Is Voluntering Rewarding in Itself ?, Economica., 75: 39-59.

Miller, Edward A. and William G. Weissert (2000). Predicting Elderly People's Risk for Nursing Nome Placement, Hospitalization, Functional Impairment, and Mortality: A Synthesis, Medical Care Research and Review. 57: 259-297.

Mirowsky, John and Catherine E. Ross (1989). Social Causes of Psychological Distress, Aldine de Gruyter.

Musick, Marc A. and John Wilson (2003). Volunteering and Depression: The Role of Psychological and Social Resources in Different Age Groups, Social Science and Medicine. 56: 259-269.

Ness, Jose, Ali Ahmed and Wilbert S. Aronow (2004). Demographic and Payment Characteristics of Nursing Home Residents in the United States: A 23-year trend, Journal of Gerontology: Medical Sciences. 59A: 1213-1217.

Onishi, Chiemi, Kyoko Yuasa, Masako Sei, Ashraf Ewis, Takuro Nakano, Hokuma Munakata and Yutaka Nakahori (2010). Determinants of Life Satisfaction among Japanese Elderly Women Attending Health Care and Welfare Service Facilities, Journal of Medical Investigation. 57: 69-80.

Penninx, Brenda W., Theo van Tilburg, Didi M. Kriegsman, Dorly J. Deeg, Joan P. Boek and Jacques van Eijk (1997). Effects of Social Support and Personal Coping Resources on Mortality in Older Age: The Longitudinal Aging Study Amsterdam, American Journal of Epidemiology. 146: 510-519.

Prouteau, Lionel and François-Charles Wolff (2004). Relational Goods and Associational Participation, Annals of Public and Cooperative Economics. 75: 431-463.

Sarmaa, Sisira and Wayne Simpson (2007). A Panel Multinomial Logit Analysis of Elderly Living Arrangements: Evidence from Aging in Manitoba Longitudinal Data, Canada, Social Science and Medicine. 65: 2539-2552.

Uchino, Bert N., John T. Cacioppo and Janice Kiecolt-Glaser (1996). The Relationship Between Social Support and Physiological Processes: A Review with Emphasis on Underlying Mechanisms and Implications for Health, Psychological Bulletin. 119: 488-531.

Uhlaner, Carole J. (1989). Relational Goods and Participation: Incorporating Sociability into a Theory of Rational Action, Public Choice. 62: 253-285.

Van Dijk, Pieter T., David R. Mehr, Marcel E. Ooms, Richard Madsen, Greg Petroski, Dinnus H. Frijters, Anne Margriet Pot and Miel W. Ribbe (2005). Comorbidity and 1-year Mortality Risks in Nursing Home Residents, Journal of American Geriatric Society. 53: 660-665. 
Table 1. Description of the sample

\begin{tabular}{|c|c|c|c|c|c|c|c|}
\hline \multirow{2}{*}{\multicolumn{3}{|c|}{ Variables }} & \multicolumn{2}{|c|}{ Living conditions } & \multicolumn{2}{|c|}{ Sadness/depression } & \multirow[t]{2}{*}{ All } \\
\hline & & & $\begin{array}{l}\text { Very bad } \\
\text { or Bad }\end{array}$ & $\begin{array}{c}\text { Well or very } \\
\text { well }\end{array}$ & $\begin{array}{l}\text { Always } \\
\text { or often }\end{array}$ & $\begin{array}{c}\text { Sometimes or } \\
\text { never }\end{array}$ & \\
\hline \multicolumn{3}{|c|}{ Female } & 0.773 & 0.762 & 0.819 & 0.768 & 0.763 \\
\hline \multicolumn{3}{|c|}{ Age } & 84.569 & 85.231 & 84.843 & 85.467 & 85.143 \\
\hline \multicolumn{3}{|c|}{ Born in France } & 0.910 & 0.918 & 0.901 & 0.921 & 0.917 \\
\hline \multirow{5}{*}{\multicolumn{2}{|c|}{ Marital status }} & Single & 0.127 & 0.166 & 0.114 & 0.150 & 0.160 \\
\hline & & Married - with spouse & 0.054 & 0.059 & 0.053 & 0.064 & 0.058 \\
\hline & & Married - spouse outside & 0.040 & 0.044 & 0.044 & 0.050 & 0.044 \\
\hline & & Widowed & 0.702 & 0.676 & 0.739 & 0.688 & 0.679 \\
\hline & & Divorced & 0.077 & 0.055 & 0.049 & 0.047 & 0.058 \\
\hline \multicolumn{3}{|c|}{ Number of children } & 2.204 & 1.914 & 2.083 & 1.982 & 1.952 \\
\hline \multirow{6}{*}{\multicolumn{2}{|c|}{ IRG }} & Level1 & 0.090 & 0.070 & 0.077 & 0.079 & 0.073 \\
\hline & & Level2 & 0.311 & 0.229 & 0.290 & 0.272 & 0.240 \\
\hline & & Level3 & 0.177 & 0.140 & 0.174 & 0.154 & 0.145 \\
\hline & & Level 4 & 0.177 & 0.240 & 0.236 & 0.231 & 0.231 \\
\hline & & Level 5 & 0.124 & 0.128 & 0.102 & 0.123 & 0.127 \\
\hline & & Level 6 & 0.120 & 0.193 & 0.120 & 0.141 & 0.183 \\
\hline \multirow[t]{3}{*}{ SAEP } & Retir & ent home & 0.773 & 0.701 & 0.727 & 0.741 & 0.711 \\
\hline & Long & m care units & 0.090 & 0.079 & 0.097 & 0.095 & 0.081 \\
\hline & Shelt & d accommodation & 0.137 & 0.220 & 0.176 & 0.164 & 0.209 \\
\hline \multicolumn{3}{|c|}{ Number of observations } & 299 & 1944 & 568 & 1372 & 2243 \\
\hline
\end{tabular}

Source: 2007 SAEP survey. 
Table 2. Random effects ordered Probit estimates of subjective well-being

A. Living conditions

\begin{tabular}{|c|c|c|c|c|c|c|c|c|c|}
\hline \multicolumn{2}{|l|}{ Variables } & \multicolumn{2}{|c|}{$\begin{array}{l}\text { (1A) All } \\
\text { respondents }\end{array}$} & \multicolumn{2}{|c|}{$\begin{array}{l}\text { (2A) All } \\
\text { respondents }\end{array}$} & \multicolumn{2}{|c|}{$\begin{array}{l}\text { (3A) Proxy } \\
\text { respondents } \\
\text { excluded }\end{array}$} & \multicolumn{2}{|c|}{$\begin{array}{l}\text { (4A) Proxy } \\
\text { respondents } \\
\text { excluded }\end{array}$} \\
\hline \multirow{2}{*}{\multicolumn{2}{|c|}{ Female }} & Coef & t-value & coef & t-value & coef & t-value & coef & t-value \\
\hline & & 0.045 & $(0.67)$ & 0.039 & $(0.58)$ & -0.055 & $(-0.69)$ & -0.038 & $(-0.47)$ \\
\hline \multicolumn{2}{|l|}{ Age } & 0.003 & $(0.76)$ & 0.003 & $(0.81)$ & 0.005 & (1.24) & 0.004 & $(0.91)$ \\
\hline \multicolumn{2}{|l|}{ Born in France } & -0.118 & $(-1.30)$ & -0.111 & $(-1.23)$ & $-0.275^{* *}$ & $(-2.28)$ & $-0.239^{* *}$ & $(-1.98)$ \\
\hline Marital status & Single & $0.138^{*}$ & (1.67) & 0.130 & (1.58) & 0.097 & $(0.99)$ & 0.132 & $(1.35)$ \\
\hline \multirow[t]{3}{*}{ (ref : Widowed) } & Married - with spouse & -0.104 & $(-0.95)$ & -0.073 & $(-0.67)$ & -0.114 & $(-0.88)$ & -0.114 & $(-0.88)$ \\
\hline & Married - spouse outside & 0.023 & $(0.18)$ & 0.041 & $(0.32)$ & 0.002 & $(0.01)$ & -0.003 & $(-0.02)$ \\
\hline & Divorced & 0.070 & $(0.62)$ & 0.053 & $(0.47)$ & 0.140 & $(1.04)$ & 0.152 & $(1.13)$ \\
\hline \multicolumn{2}{|c|}{ Number of children } & -0.018 & $(-1.23)$ & -0.018 & $(-1.22)$ & -0.025 & $(-1.41)$ & -0.025 & $(-1.39)$ \\
\hline \multicolumn{2}{|c|}{ IRG score } & $0.072^{* * *}$ & $(3.60)$ & $0.056^{* * *}$ & $(2.79)$ & $0.087^{* * *}$ & $(3.64)$ & $0.075^{* * *}$ & (3.14) \\
\hline SAEP & Long term care units & -0.090 & $(-0.87)$ & -0.052 & $(-0.52)$ & -0.096 & $(-0.66)$ & -0.109 & $(-0.75)$ \\
\hline (ref : Retir. home) & Sheltered accommodation & $0.343^{* * *}$ & $(4.43)$ & $0.322^{* * *}$ & $(4.26)$ & $0.277^{* * *}$ & (3.03) & $0.259^{* * *}$ & $(2.85)$ \\
\hline \multicolumn{2}{|c|}{ Proxy respondents } & -0.093 & $(-1.47)$ & -0.042 & $(-0.67)$ & & & & \\
\hline \multicolumn{2}{|c|}{ Friends in the nursing home } & & & $0.532^{* * *}$ & $(9.40)$ & $0.639^{* * *}$ & (8.75) & $0.633^{* * *}$ & (8.67) \\
\hline \multicolumn{2}{|c|}{ Visited by family/relatives } & & & & & $0.208^{* *}$ & $(2.17)$ & -0.148 & $(-1.30)$ \\
\hline \multicolumn{2}{|c|}{ Satisfied with frequency of visits from family/relatives } & & & & & & & $0.470^{* * *}$ & $(5.81)$ \\
\hline \multicolumn{2}{|c|}{$\rho$} & 0.080 & & 0.066 & & 0.119 & & 0.114 & \\
\hline \multicolumn{2}{|c|}{ Number of observations } & 2243 & & 2243 & & 1627 & & 1627 & \\
\hline \multicolumn{2}{|c|}{ Number of institutions } & 418 & & 418 & & 400 & & 400 & \\
\hline \multicolumn{2}{|c|}{ Log likelihood } & -2283.9 & & -2239.7 & & -1156.6 & & -1539.7 & \\
\hline \multicolumn{10}{|c|}{ B. Sadness/depression } \\
\hline \multicolumn{2}{|l|}{ Variables } & \multicolumn{2}{|c|}{$\begin{array}{l}\text { (1B) All } \\
\text { respondents }\end{array}$} & \multicolumn{2}{|c|}{$\begin{array}{l}\text { (2B) All } \\
\text { respondents }\end{array}$} & $\begin{array}{l}\text { (3B) Prox } \\
\text { responde } \\
\text { excluded }\end{array}$ & & $\begin{array}{l}\text { (4B) Prox } \\
\text { responde } \\
\text { excluded }\end{array}$ & \\
\hline Female & & $\begin{array}{l}\text { coef } \\
-0.229^{* * *}\end{array}$ & $\begin{array}{l}\text { t-value } \\
(-3.56)\end{array}$ & $\begin{array}{l}\text { coef } \\
-0.234^{* * *}\end{array}$ & $\begin{array}{l}\text { t-value } \\
(-3.63)\end{array}$ & $\begin{array}{l}\text { coef } \\
-0.269^{* * *}\end{array}$ & $\begin{array}{l}\text { t-value } \\
(-3.63)\end{array}$ & $\begin{array}{l}\text { coef } \\
-0.256^{* * *}\end{array}$ & $\begin{array}{l}\text { t-value } \\
(-3.46)\end{array}$ \\
\hline Age & & $0.012^{* * *}$ & (3.74) & $0.012^{* * *}$ & (3.79) & $0.011^{* * *}$ & $(2.73)$ & $0.009^{* *}$ & (2.37) \\
\hline Born in France & & 0.115 & $(1.34)$ & 0.123 & (1.44) & 0.053 & $(0.49)$ & 0.088 & $(0.81)$ \\
\hline Marital status & Single & $0.285^{* * *}$ & (3.63) & $0.282^{* * *}$ & (3.58) & $0.273^{* * *}$ & $(3.00)$ & $0.307^{* * *}$ & (3.38) \\
\hline (ref : Widowed) & Married - with spouse & 0.075 & $(0.72)$ & 0.092 & (0.87) & 0.084 & (0.69) & 0.089 & $(0.74)$ \\
\hline & Married - spouse outside & 0.156 & $(1.28)$ & 0.166 & $(1.36)$ & 0.179 & $(1.12)$ & 0.175 & (1.10) \\
\hline & Divorced & $0.283^{* * *}$ & (2.63) & $0.276^{* *}$ & $(2.56)$ & $0.354^{* * *}$ & $(2.82)$ & $0.370^{* * *}$ & $(2.95)$ \\
\hline Number of childre & & -0.013 & $(-0.87)$ & -0.013 & $(-0.87)$ & -0.018 & $(-1.08)$ & -0.017 & $(-1.01)$ \\
\hline IRG score & & $0.047^{* *}$ & $(2.45)$ & $0.038^{* *}$ & (1.97) & $0.068^{* * *}$ & (3.11) & $0.057^{* * *}$ & $(2.58)$ \\
\hline SAEP & Long term care units & -0.107 & $(-1.13)$ & -0.088 & $(-0.94)$ & -0.035 & $(-0.28)$ & -0.044 & $(-0.36)$ \\
\hline (ref : Retir. home) & Sheltered accommodation & $0.122^{*}$ & (1.77) & 0.110 & (1.61) & 0.089 & (1.18) & 0.069 & $(0.94)$ \\
\hline Proxy respondent & & $-0.245^{* * *}$ & $(-4.04)$ & $-0.220^{* * *}$ & $(-3.61)$ & & & & \\
\hline Friends in the nur & sing home & & & $0.268^{* * *}$ & $(4.95)$ & $0.311^{* * *}$ & $(4.62)$ & $0.302^{* * *}$ & $(4.50)$ \\
\hline Visited by family/r & elatives & & & & & 0.142 & $(1.60)$ & $-0.202^{*}$ & $(-1.91)$ \\
\hline Satisfied with frea & uency of visits from family/relatives & & & & & & & $0.450^{* * *}$ & $(5.99)$ \\
\hline$\rho$ & & 0.043 & & 0.039 & & 0.031 & & 0.022 & \\
\hline Number of observ & ations & 2243 & & 2243 & & 1627 & & 1627 & \\
\hline Number of institu & tions & 418 & & 418 & & 400 & & 400 & \\
\hline Log likelihood & & -2632.6 & & -2620.4 & & -1871.4 & & -1853.5 & \\
\hline
\end{tabular}

Source: 2007 SAEP survey.

Note: estimates from random effect ordered Probit models. Absolute values of $t$ statistics are in brackets, significance levels being equal to $1 \%\left({ }^{* * *}\right), 5 \%\left(\left(^{* *}\right)\right.$ and $10 \%\left({ }^{*}\right)$. Each regression also includes a set of six occupational dummies. 
Table 3. Random effect ordered Probit estimates of changes in living conditions

\begin{tabular}{lllll}
\hline Variables & \multicolumn{2}{l}{ (1) All respondents } & \multicolumn{2}{l}{ (2) Proxy respondents excluded } \\
\hline & coef & t-test & coef & t-test \\
Female & 0.035 & $(0.59)$ & 0.055 & $(0.80)$ \\
Age & -0.005 & $(-1.57)$ & -0.003 & $(-0.82)$ \\
Years in retirement home & $-0.015^{* * *}$ & $(-3.18)$ & $-0.015^{* * *}$ & $(-2.80)$ \\
IRG score & -0.004 & $(-0.24)$ & 0.009 & $(0.41)$ \\
Proxy respondents & -0.051 & $(-0.80)$ & & $(2.30)$ \\
Friends in the nursing home & $0.130^{* *}$ & $(2.30)$ & $0.164^{* *}$ & 0.098 \\
\hline$\rho$ & 0.077 & & 1596 & \\
\hline Number of observations & 2176 & & 400 & \\
Number of institutions & 418 & & -1645.3 & \\
Log likelihood & -2406.9 & & & \\
\hline
\end{tabular}

Source: 2007 SAEP survey.

Note: estimates from random effect ordered Probit models. Absolute values of $t$ statistics are in brackets, significance levels being equal to $1 \%\left({ }^{* * *}\right), 5 \%\left({ }^{* *}\right)$ and $10 \%\left({ }^{*}\right)$. 
Figure 1.Initial and current living conditions of respondents

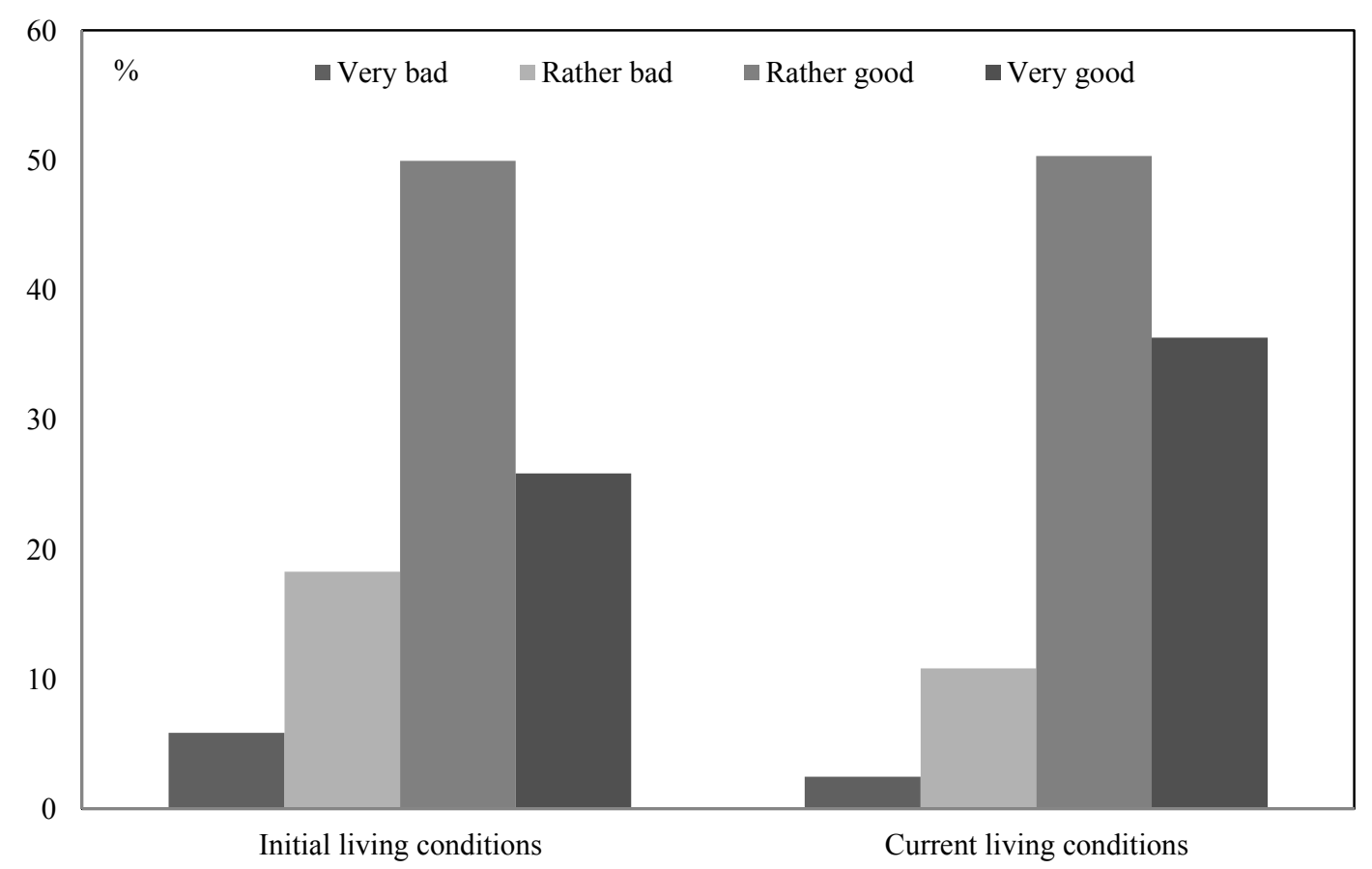

Source: 2007 SAEP Survey. 
Figure 2. Subjective well-being of respondents and friends A. Living conditions

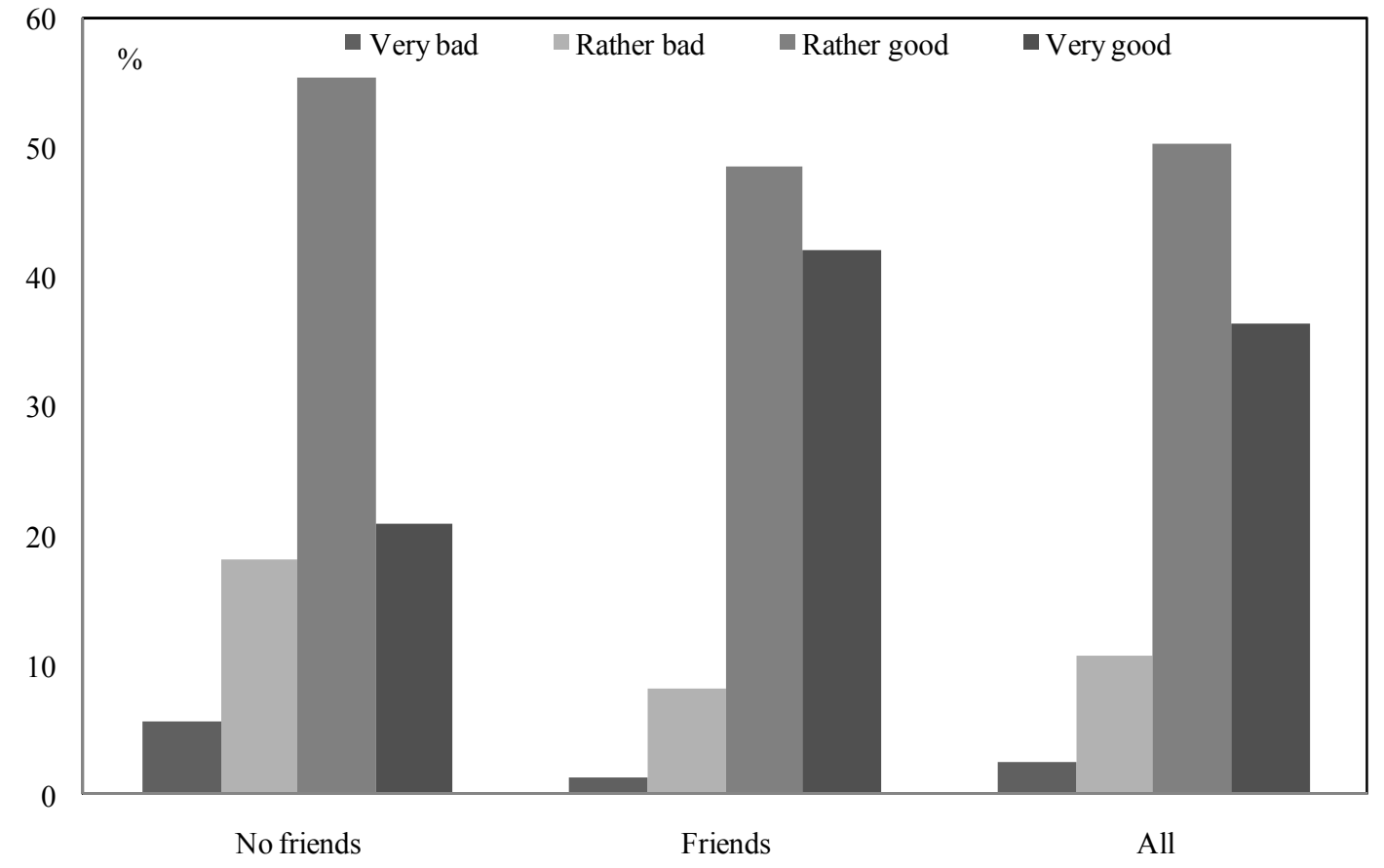

B. Sadness/depression

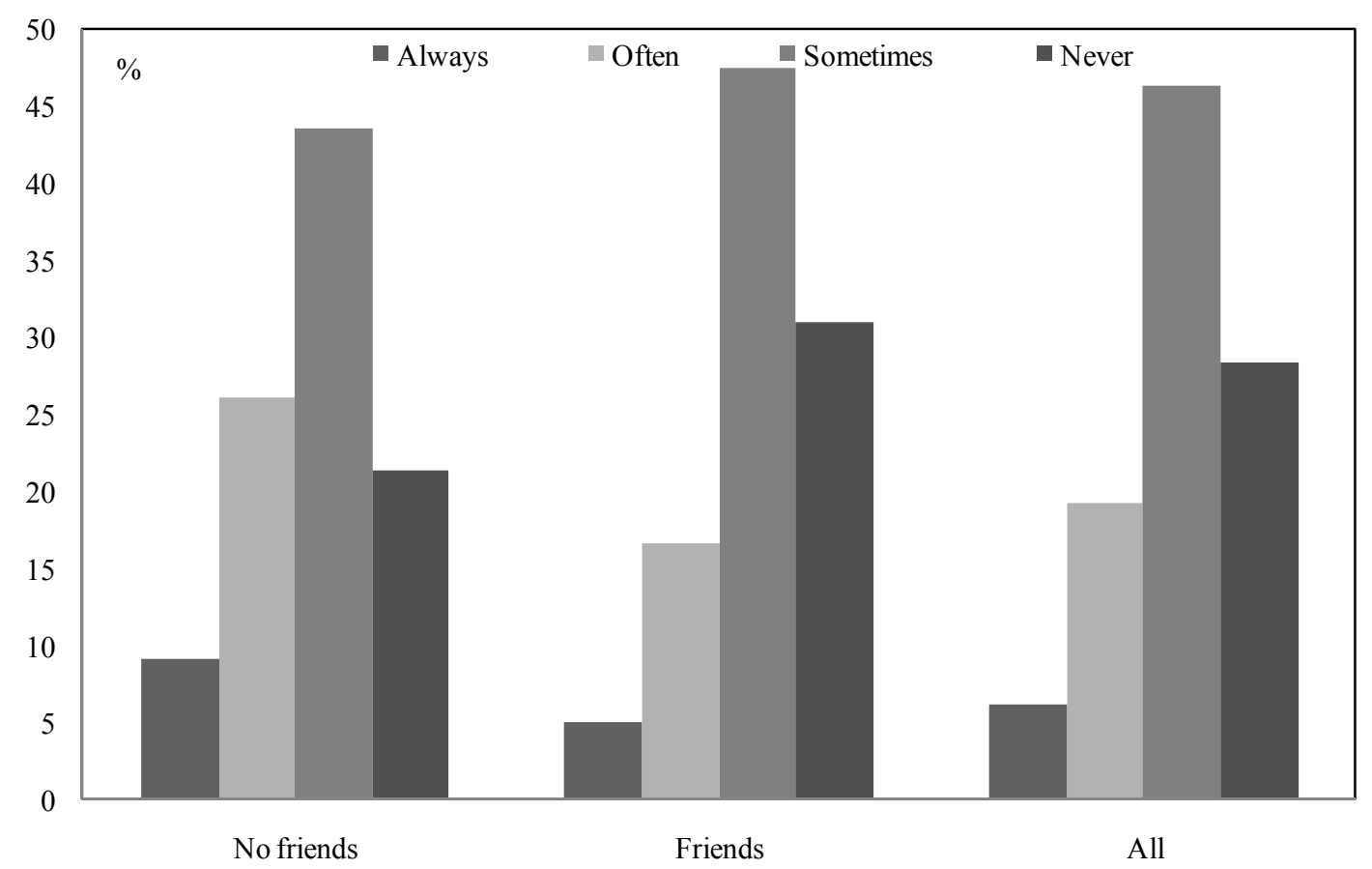

Source: 2007 SAEP Survey. 